\title{
The acidic tumor microenvironment drives a stem-like phenotype in melanoma cells
}

\author{
Elena Andreucci ${ }^{1}$ (D) Silvia Peppicelli ${ }^{1}$ (D) - Jessica Ruzzolini ${ }^{1} \cdot$ Francesca Bianchini ${ }^{1} \cdot$ Alessio Biagioni $^{1}$. \\ Laura Papucci $^{1}$ - Lucia Magnelli $^{1}$ • Benedetta Mazzanti ${ }^{2} \cdot$ Barbara Stecca $^{3} \cdot$ Lido Calorini $^{1,4}$
}

Received: 25 November 2019 / Revised: 14 July 2020 / Accepted: 5 August 2020 / Published online: 15 August 2020

(C) The Author(s) 2020

\begin{abstract}
Acidosis characterizes the microenvironment of most solid tumors and is considered a new hallmark of cancer. It is mainly caused by both "aerobic" and "anaerobic" glycolysis of differently adapted cancer cells, with the final product lactic acid being responsible of the extracellular acidification. Many evidences underline the role of extracellular acidosis in tumor progression. Among the different findings, we demonstrated that acidosis-exposed cancer cells are characterized by an epithelial-tomesenchymal transition phenotype with high invasive ability, high resistance to apoptosis, anchorage-independent growth, and drug therapy. Acidic melanoma cells over-express SOX2, which is crucial for the maintenance of their oxidative metabolism, and carbonic anhydrase IX, that correlates with poor prognosis of cancer patients. Considering these evidences, we realized that the profile outlined for acid cancer cells inevitably remind us the stemness profile. Therefore, we wondered whether extracellular acidosis might induce in cancer cells the acquisition of stem-like properties and contribute to the expansion of the cancer stem cell sub-population. We found that a chronic adaptation to acidosis stimulates in cancer cells the expression of stem-related markers, also providing a high in vitro/in vivo clonogenic and trans-differentiating ability. Moreover, we observed that the acidosisinduced stem-like phenotype of melanoma cells was reversible and related to the EMT induction. These findings help to characterize a further aspect of stem cell niche, contributing to the sustainment and expansion of cancer stem cell subpopulation. Thus, the usage of agents controlling tumor extracellular acidosis might acquire great importance in the clinic for the treatment of aggressive solid tumor.
\end{abstract}

\section{Key messages}

- Extracellular acidosis up-regulates EMT and stem-related markers in melanoma cells

- Acidic medium up-regulates in vitro self-renewal capacity of melanoma cells

- Chronic acidosis adaptation induces trans-differentiation ability in melanoma cells

- Melanoma cells adapted to acidosis show higher tumor-initiating potential than control cells

- Extracellular acidosis promotes a stem-like phenotype in prostate and colorectal carcinoma cells

Keywords Acidosis $\cdot$ Tumor microenvironment $\cdot$ Melanoma $\cdot$ Cancer stem cells

Elena Andreucci and Silvia Peppicelli contributed equally to this work.

Elena Andreucci

e.andreucci@unifi.it

Silvia Peppicelli

silvia.peppicelli@unifi.it

1 Department of Experimental and Clinical Biomedical Sciences "Mario Serio", Section of Experimental Pathology and Oncology, University of Florence, Florence, Italy
2 Haematology Unit, Department of Experimental and Clinical Medicine, University of Florence, Florence, Italy

3 Tumor Cell Biology Unit - Core Research Laboratory, Institute for Cancer Research, Prevention and Clinical Network (ISPRO), Florence, Italy

4 Center of Excellence for Research, Transfer and High Education DenoTHE, University of Florence, Florence, Italy 


\section{Abbreviations \\ CAIX Carbonic anhydrase IX \\ CSC Cancer stem cells \\ ELDA Extreme limiting dilution analysis \\ EMT Epithelial-to-mesenchymal transition \\ TIC Tumor-initiating cells}

\section{Introduction}

Several evidences suggest that cancer stem cells (CSC) are the ultimate responsible of not only tumor initiation but also metastatic disease. CSC represent indeed the only cell population within the tumor bulk with tumor-initiating and self-renewal abilities, so that they are likely the unique cancer subpopulation able to generate organ metastases [1].

Among several solid tumors, various reports indicate that melanomas are particularly enriched in CSC [2] and indeed considered one of the most aggressive cancers [3]. Melanoma cells display high phenotypic heterogeneity, expression of developmental genes, differentiation plasticity, and high tumorigenicity supporting the presence of a high number of CSC [4]. Melanoma cells often display some characteristics of neural cells [4] and are capable to organize vessel-like structures mimicking the endothelial cells, undergoing the so-called vasculogenic mimicry [5]. In specific conditions, melanoma cells may also acquire fibroblastic or adipogenic differentiation markers [6]. Quintana and colleagues reported that the incidence of tumorigenic cells in melanoma is greater over that observed for any other human cancer type [7]. Interestingly, by deeply investigating the tumorigenic and non-tumorigenic subpopulations, they did not find any significant phenotypic differences that could account for the diverse tumorigenic ability of these two populations [7]. They thus underlined the importance to investigate the role of epigenetic, genetic, and also environmental factors in inducing tumorigenicity. This represents an intriguing starting point to investigate how tumor microenvironment could influence cancer progression toward malignancy. An embryonic microenvironment has been shown to revert melanoma cells toward a more benign phenotype [8], while many evidences suggested that environmental factors such hypoxia and extracellular acidosis are critical for melanocyte transformation and progression toward malignancy [9-13].

Acidosis of tumor microenvironment is almost an obligatory step associated with the high proliferative rate of cancer cells exploiting glycolysis not only when oxygen tension reduces (anaerobic glycolysis) but even in the presence of sufficient oxygen to sustain oxidative phosphorylation (i.e., near blood vessels) (aerobic glycolysis or "Warburg effect"), with a subsequent lactic acid release [14]. Moreover, also the mitochondrial respiration, through the spontaneous or enzymatic $\mathrm{CO}_{2}$ hydration to carbonic acid, contributes to the extracellular medium acidification [15]. As a direct consequence, almost all solid tumors experience extracellular acidosis (ranging a pH from 6.4 to 7.0) [16], which is also caused by reduced lymphatic circulation and high interstitial pressure [17]. Many evidences highlighted the role of extracellular acidosis in the acquisition of tumor aggressive features, so that it is now recognized as a hallmark of cancer $[9,18,19]$. In the last years, we contributed to disclose most of the promoting effects of extracellular acidosis towards tumor malignancy, and the profile we delineated for the acid-adapted tumor cells inevitably reminds us the one proposed for CSC. Indeed, extracellular acidosis stimulates in various types of cancer several aspects related to stemness. Besides disclosing that acidadapted melanoma cells overexpress well-known stem-related markers (i.e., SOX2 - that sustains the oxidative metabolism exploited under acidosis [20] — and CAIX [21] — that, proposed as a marker of the pre-metastatic niche, always associates with resistant phenotype and correlates with very poor prognosis of tumor patients), we and other research groups demonstrated that extracellular acidosis induces the epithelial-to-mesenchymal transition (EMT) program [22-25], associated with a reduced proliferation rate, a high metalloprotease-dependent invasive ability $[25,26]$, and high apoptotic resistance in tumor cells $[25,27,28]$. Importantly, as we already reported [25], extracellular acidosis increases melanoma cell metastatic potential by triggering an "incomplete" or "partial" EMT program, that allows tumor cells to coexpress mesenchymal and epithelial traits at the same time, and to be prompt to undergo the reverse mesenchymal-toepithelial transition (MET) program at convenience during the metastatic cascade, a distinct sign of the high-plastic tumor phenotype induced by the acidic microenvironment. Another important trait of acidic cancer cell defining a high-resistant tumor phenotype is the anoikis resistance that we found significantly increased upon acidic exposure of melanoma cells [11]. Anoikis resistance is a crucial aspect for aggressive tumor cell subpopulation that, once detached from the primary mass, must survive into blood stream before their secondary lodgment. In addition, as a further indication of acidosisinduced resistant phenotype, acidic BRAF-mutated melanoma cells were found to not respond to targeted and standard chemotherapy, confirming the great impact of acidic tumor microenvironment in cancer progression [12].

Thus, we have investigated if an acidic tumor microenvironment could actually promote the expansion of the CSC subpopulation by inducing the acquisition of critical stem-like features in tumor cells. To investigate the influence of extracellular acidosis on stemness, cancer cells were chronically exposed to $\mathrm{pH} 6.7 \pm 0.1$ (which is the $\mathrm{pH}$ generally found in solid tumors, including melanoma) and considered "acid-adapted" when they recovered a proliferation rate similar to control cells maintained at standard $\mathrm{pH}[27,29]$. 


\section{Methods}

\section{Cell cultures}

Melanoma cell lines A375M6 [20] and M21 (kindly provided by Dr. Antony Montgomery, The Scripps Research Institute, La Jolla, CA), prostate cell line PC3 (purchased from the American Type Culture Collection, ATCC, Rockville, MD) and colon cancer cell line HCT116 (a kind gift of Dr. Matteo Lulli, Department of Clinical and Experimental Biomedical Sciences "Mario Serio", University of Florence, Italy) [30], STR profiled and mycoplasma tested, were cultured in DMEM $4.5 \mathrm{~g} / 1$ glucose, $2 \mathrm{mM}$ L-glutamine, and 10\% FBS (Euroclone, Milan Italy). The chronic extracellular acidic condition was mimicked in vitro as previously reported [11]. Briefly, chemical acidified medium was obtained by adding $\mathrm{HCl} 1 \mathrm{~N}$ in complete culture medium to reach $\mathrm{pH} 6.7 \pm 0.1$. $\mathrm{pH}$ value was monitored by using Orion $\mathrm{pH}$ meter 520A-1 at regular intervals during the first hour after the acidification to check the maintenance of correct $\mathrm{pH}$ of the medium. To obtain chronic acidic cultures, cancer cells were constantly subjected to a pH 6.7 medium for at least 3 months, until they recovered a similar growth rate as parent cells maintained at standard $\mathrm{pH}$ 7.4 condition. During the long-lasting acidic treatment, no significant death of cells was found.

\section{MTT assay}

Cell viability was assessed using MTT (3-(4,5-dimethylthiazol-2-yl)-2,5-diphenyltetrazolium bromide) tetrazolium reduction assay (Sigma Aldrich, Milan, Italy) as previously described. Control or acid-adapted cancer cells were plated into 96-multiwell plates in complete medium without red phenol. After 24, 48, or $72 \mathrm{~h}$ the MTT reagent was added to the medium and plates were incubated at $37^{\circ} \mathrm{C}$. After $3 \mathrm{~h}$, MTT was removed and the blue MTT-formazan product was solubilized with dimethyl sulfoxide (DMSO) (Sigma Aldrich). The absorbance of the formazan solution was read at $595 \mathrm{~nm}$ using the microplate reader (Bio-Rad, Milan, Italy).

\section{Flow cytometry}

Cells were harvested by using Accutase (Euroclone, Milan, Italy), collected in flow cytometer tubes $\left(2 \times 10^{5}\right.$ cells/tube), and stained $1 \mathrm{~h}$ at $4{ }^{\circ} \mathrm{C}$ with anti-CD133 (Affimetrix eBioscience, part of Thermo Fisher Scientific, Monza, Italy), anti-CD243 (Affimetrix eBioscience), anti-CD34 (BD PharMingen, San Diego, CA), anti-CD105 (Ancell, Bayport, MN), anti-CD73 (BD PharMingen), and anti-CD90 (BD PharMingen) antibodies. For intracellular antigen detection, cells were permeabilized for 15 min with $0.25 \%$ Tryton X$100 \mathrm{PBS}$, and then incubated $1 \mathrm{~h}$ at $4{ }^{\circ} \mathrm{C}$ with anti-ALDH1A1 (Abcam, Milan, Italy), anti-Nanog (GeneTex, CA, USA),
anti-KLF4 (GeneTex), anti-OCT4 (GeneTex), and antiSOX2 (GeneTex) antibodies. Cells were washed in PBS and incubated $1 \mathrm{~h}$ in the dark at $4{ }^{\circ} \mathrm{C}$ with secondary antibodies conjugated with FITC (Merk Millipore, Milan, Italy), Alexa Fluor 488 (Thermo Fisher Scientific, Monza Italy), PE (Immunotools, Germany), or APC (Immunotools). Samples were washed in PBS and analyzed at BD FACSCanto (BD Biosciences, Milan, Italy). The flow cytometer was calibrated using cells incubated with secondary antibody only. For each sample, $1 \times 10^{4}$ events were analyzed.

\section{Tumorsphere formation assay}

Control or acid-adapted cancer cells were plated at 150 cells/ $\mathrm{cm}^{2}$ on a low-attachment $100 \mathrm{~mm}$ plate in DMEM/F12 sup-

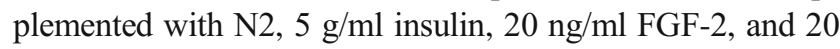
$\mathrm{ng} / \mathrm{ml}$ EGF (all from Thermo Fisher Scientific) at standard $\mathrm{pH}$. Cells were allowed to form tumorspheres by $10-15$ days. For serial passaging, 10-day-old tumorspheres were dissociated in single cells with Accutase (Euroclone), and plated at 150 cells/ $\mathrm{cm}^{2}$ on a low-attachment $100 \mathrm{~mm}$ plate for 10 additional days.

\section{In vitro limiting dilution assay}

Control or acid-adapted cancer cells were seeded into ultralow attachment 96-well plate at different cell doses, with a maximum of 100 cells per well and a minimum of one cell per well, and incubated in spheroid-forming conditions for 10 days at $37^{\circ} \mathrm{C}$, at standard $\mathrm{pH}$. Colony formation was assessed by visual inspection. For each dilution series, we counted wells that showed sphere formation on day 11. Data were analyzed and displayed using the Extreme limiting dilution assay (ELDA) software available at http://bioinf.wehi.edu. $\mathrm{au} /$ software/elda/ [31].

\section{Western blotting analysis}

Cells were washed with ice cold PBS containing $1 \mathrm{mM}$ $\mathrm{Na}_{4} \mathrm{VO}_{3}$, and lysed in $100 \mu \mathrm{l}$ of cell RIPA lysis buffer (Merk Millipore) containing PMSF (Sigma-Aldrich), sodium orthovanadate (Sigma-Aldrich), and protease inhibitor cocktail (Merk Millipore) as previously described [11]. Aliquots of supernatants containing equal amounts of protein $(50-100 \mu \mathrm{g})$ in Bolt LDS Sample Buffer (Thermo Fisher Scientific) were separated on Bolt@ Bis-Tris Plus gels $4-12 \%$ precast polyacrylamide gels (Thermo Fisher Scientific). Fractionated proteins were transferred from the gel to a PVDF nitrocellulose membrane using an electroblotting apparatus (Bio-Rad, Segrate, MI, Italy). Blots were blocked for $1 \mathrm{~h}$, at room temperature, with Odyssey blocking buffer (Dasit Science, Cornaredo, MI, Italy), and the membrane was probed at 4 ${ }^{\circ} \mathrm{C}$ overnight with primary antibodies diluited in a solution of 1:1 Odyssey blocking buffer/T-PBS buffer. The primary 
antibodies were mouse anti-Nanog, mouse anti-Oct4, mouse anti-NFkB p65 (1:500, GeneTex), mouse anti-Vimentin, rabbit anti-Zeb1 (1:1000, Santa Cruz Biotechnology, Santa Cruz, California), rabbit anti-Slug (1:500, Cell signaling Technology, Danvers, MA, US), rabbit anti-Snai1 (1:500, Biorbyt, Cambridge, United Kingdom), and mouse anti NCadherin (1:1000, DAKO Agilent, Milan, Italy). The membrane was washed in T-PBS buffer, incubated for $1 \mathrm{~h}$ at room temperature with goat anti-rabbit IgG Alexa Flour 750 antibody or with goat anti-mouse IgG Alexa Fluor 680 antibody (Invitrogen, Monza, Italy), and then visualized by an Odyssey Infrared Imaging System (LI-COR $®$ Bioscience). Mouse anti- $\beta$-tubulin monoclonal antibody (Sigma, Saint Louis, MO, USA) was used to assess equal amount of protein loaded in each lane.

\section{siRNA transfection}

For transfections, control siRNA (siCTRL, Thermo Fisher Scientific) and siRNA for RelA (NF-kB coding gene) (siRELA, Thermo Fisher Scientific) were diluted in Optimem medium (Thermo Fisher Scientific) to a final concentration of $5 \mathrm{nM}$ and $50 \mathrm{nM}$ for A375M6 and M21, respectively. Transfections were performed using Lipofectamine 3000 reagent (Thermo Fisher Scientific), following the manufacturer's instructions.

\section{Mouse xenograft assays}

Six-week-old female CD-1 nude mice (Charles River, Calco, Lecco, Italy) were injected subcutaneously in lateral flanks with $10^{2}$ and $10^{3}$ A375M6 and M21 melanoma cells suspended in Matrigel (BD Biosciences)/DMEM (1:1) (DMEM at standard $\mathrm{pH}$ 7.4). Six animals for each cell line and dilution were used for the experiments, in order to get a statistically significant data and at the same time to accomplish to the $3 \mathrm{R}$ principle (Replacement, Reduction, and Refinement). Animals were monitored daily; subcutaneous tumor size was measured every 2-3 days by a caliper, and tumor volumes calculated using the formula $V=4 / 3 \pi \times W / 2$ $\times(L / 2)^{2}$, where $W$ and $L$ are, respectively, tumor width (perpendicular tumor diameter) and length (largest tumor diameter). Mice were sacrificed before showing evident signals of discomfort with an overdose of isoflurane. Statistical analysis of tumor take was performed using the ELDA software [31]. Experiments with animals were conducted in accordance with national guidelines and were approved by the ethics committee of the Animal Welfare Office of the Italian Ministry of Health (n401/2015/PR) and conformed to the legal mandates and Italian guidelines for the care and maintenance of laboratory animals.

\section{Adipocyte and osteocyte melanoma cell differentiation}

Sub-confluent melanoma cells seeded in 6-well plate were treated with pro-adipogenic differentiating mediumDMEM $1 \mathrm{~g} / \mathrm{L}$ glucose supplemented with $10 \%$ FBS (Euroclone), $0.5 \mathrm{mM}$ isobutyl methylxanthine, $1 \mu \mathrm{M}$ dexamethasone, $10 \mu \mathrm{g} / \mathrm{ml}$ of insulin, and $70 \mu \mathrm{M}$ indomethacin (Sigma Aldrich)—or pro-osteogenic differentiating medium-DMEM $1 \mathrm{~g} / \mathrm{L}$ glucose supplemented with $10 \%$ FBS (Euroclone), $10 \mathrm{nM}$ dexamethasone, $100 \mu \mathrm{g} / \mathrm{ml}$ ascorbic acid, and $10 \mathrm{mM} \beta$-glycerophosphate (Sigma Aldrich)-for 3 weeks. Pro-adipogenic and pro-osteogenic differentiating media were prepared and administered at standard $\mathrm{pH}$. Media were replaced every other day. Lipid drops of adipogenicdifferentiated melanoma cells were stained by Oil Red O (Sigma Aldrich): briefly, cells were fixed for $30 \mathrm{~min}$ at room temperature in $4 \%$ formaldehyde, then the stock solution (30 mg Oil Red O powder $/ 10 \mathrm{ml}$ isopropanol) was diluted 3:2 (V:V) in deionized $\mathrm{H}_{2} \mathrm{O}$ and fixed cells stained for 5 min. Calcium deposits of osteoblast-like-differentiated melanoma cells were stained with Alizarin Red (Sigma Aldrich): briefly, cells were fixed in $70 \%$ ethanol for $1 \mathrm{~h}$ at $4{ }^{\circ} \mathrm{C}$ and stained for 10 min with $40 \mathrm{mM}$ Alizarin Red solution in deionized $\mathrm{H}_{2} \mathrm{O}$ at $\mathrm{pH} 4.2$.

To quantify adipocyte and osteoblast-like differentiation of melanoma cells, qPCR analysis was performed for proadipogenic (LPL, CEBP $\alpha$ and PPAR $\gamma$ ) and pro-osteogenic (ALPL, COL1A1, DMP1, and SOST) differentiation genes.

\section{Quantitative real-time PCR}

Total RNA was prepared using Tri Reagent (Sigma-Aldrich), agarose gel checked for integrity, and reverse transcribed with iScript cDNA Synthesis Kit (Bio-Rad) according to the manufacturer's instructions. Selected genes were evaluated by a real-time qPCR with 7500 Fast Real-Time PCR System (Applied Biosystems, Monza, Italy). Fold change was determined by the comparative $\mathrm{Ct}$ method calculating the average of $\beta$-actin, $\beta 2$-microglobulin, TATA-Box Binding Protein (TBP), and $18 \mathrm{~s}$ used as reference genes. Amplification was performed with the PCR setting: 40 cycles of $95{ }^{\circ} \mathrm{C}$ for $15 \mathrm{~s}$ and of $60{ }^{\circ} \mathrm{C}$ for $60 \mathrm{~s}$ using PowerUp SYBR Green Master Mix (Thermo Fisher Scientific). Primer sequences (IDT, Tema Ricerca, Bologna, Italy) are listed in Table 1 ( $\beta$-actin, $\beta 2$-microglobulin, TBP, and 18s used as reference genes).

\section{Statistical analysis}

The experiments were performed at least five times for a reliable application of statistics. All samples used were included in the statistical analysis. Statistical analysis was performed by $T$ test, One-way analysis of variance (ANOVA), and Two- 
Table 1 Primer sequences for real-time PCR analysis

\begin{tabular}{lll}
\hline Gene & Forward $\left(5^{\prime}\right.$-3') & Reverse $\left(5^{\prime}\right.$-3') \\
\hline$\beta 2$-microglobulin & GCCGTGTGAACCATGTGACT & GCTTACATGTCTCGATCCCACTT \\
$\beta$-actin & TCGAGCCATAAAAGGCAACT & CTTCCTCAATCTCGCTCTCG \\
$18 \mathrm{~s}$ & CGCCGCTAGAGGTGAAATTCT & CGAACCTCCGACTTTCGTTCT \\
TBP & CAACAGCCTGCCACCTTAC & CTGAATAGGCTGTGGGGTC \\
N-cadherin & CACTGCTCAGGACCCAGAT & TAAGCCGAGTGATGGTCC \\
E-cadherin & CGGGAATGCAGTTGAGGATC & AGGATGGTGTAAGCGATGGC \\
Twist & CGGGAGTCCGCAGTCTTA & TGAATCTTGCTCAGCTTGTC \\
Snail & CCCAGTGCCTCGACCACTAT & CCAGATGAGCATTGGCAG \\
Vimentin & TGTCCAAATCGATGTGGATGTTTC & TTGTACCATTCTTCTGCCTCCTG \\
LPL & TCCGCGTGATTGCAGAGA & GCTCGTGGGAGCACTTCACT \\
CEBP $\alpha$ & GGGTCTGAGACTCCCTTTCCTT & CTCATTGGTCCCCCAGGAT \\
PPAR $\gamma$ & TCAGGGCTGCCAGTTTCG & GCTTTTGGCATACTCTGTGATCTC \\
ALPL & CCGTGGCAACTCTATCTTTGG & GATGGCAGTGAAGGGCTTCTT \\
COL1A1 & CTGTTCTGTTCCTTGTGTAACTGTGTT & GCCCCGGTGACACATCAA \\
DMP1 & ACATTGAGATAGAGAGCCGGAAA & TGGTCCCCAATGGGTTTGT \\
SOST & TCAGAGGAGGCAGAAATGGAA & CCACACCGCTCCCTTAAAAC \\
\hline
\end{tabular}

way ANOVA with GraphPad Prism 6 software, as specified in each figure legend. Statistical significances were accepted at $p$ $<0.05$. Values are presented as mean of independent experiments \pm SD.

\section{Results}

\section{Extracellular acidosis up-regulates EMT and stem- related markers in melanoma cells}

A375M6 and M21 melanoma cells were exposed to $\mathrm{pH} 6.7$ for approximately 3 months and considered "acid-adapted" when they recovered a proliferation rate similar to control cells maintained at standard pH (Fig. 1a). Chronic adaptation to extracellular acidosis, as well as acute exposure [25], induces a partial EMT program, a feature related to stemness [32], by maintaining the expression levels of the epithelial marker Ecadherin and at the same time inducing the acquisition of the mesenchymal markers N-cadherin and Twist in both A375M6 and M21 cell lines, Snail and Vimentin in only A375M6 cells (Fig. 1b).

Acid-adapted cells, previously shown to over-express CAIX [21] - a marker of CSC strongly associated with drug resistance [33, 34] - also show a higher percentage of CD133-CAIX co-expressing cells than control (Fig. 1c). Following these findings, we evaluated, by flow cytometry analysis, the expression of a panel of stem-related proteins, observing a significant increase of CD133, CD243, ALDH1A1, NANOG, and SOX2 for acid-adapted A375M6 and of ALDH1A1, NANOG, KLF4, and OCT4 for acidadapted M21 cells compared with control (Fig. 1d).

\section{Extracellular acidosis up-regulates self-renewal ca- pacity of melanoma cells in vitro}

One of the most important property of CSC is the selfrenewal potential, tested in vitro as the ability of melanoma cells to form tumorspheres. Acid-adapted A375M6 and M21 cells gave rise to higher number of melanospheres than control, and such ability is further enhanced along with the serial passages (Fig. 2a). These results were confirmed using a limiting dilution assay, where acid-adapted or control cells were evaluated for sphere formation 10 days later cell plating. By extreme limiting dilution analysis (ELDA) software analysis [31], acid-adapted melanoma cells showed a significant increase in tumor-initiating cells (TIC), from 18.7 to $33.7 \%$ for A375M6 and from 20 to $33.6 \%$ for M21 cells, suggesting that the low $\mathrm{pH}$ is able to expand the selfrenewal population (Fig. 2b).

\section{Reversibility of the acidosis-induced stem-like phe- notype in melanoma cells}

Since CSC have been described as dynamic, able to exhibit plasticity and to revert their stem cell properties [35], we grown back acid-adapted melanoma cells in standard $\mathrm{pH}$ medium for 15 days and obtained tumor subpopulations thereafter referred to as " $\mathrm{pH} 7.4$ restored" ( $\mathrm{pH} 7.4 \mathrm{R})$. By western blot analysis, we observed that the expression levels of the stem-related markers Nanog and Oct4, significantly increased in acid-adapted melanoma cells, did not vary in $\mathrm{pH} 7.4 \mathrm{R}$ A375M6, while Nanog expression was significantly reduced in $\mathrm{pH}$ 7.4R M21 (Fig. 3a). 
a

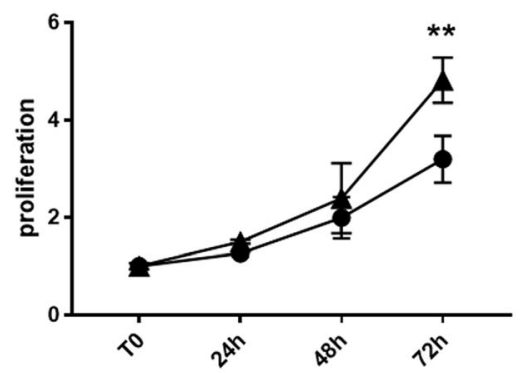

b

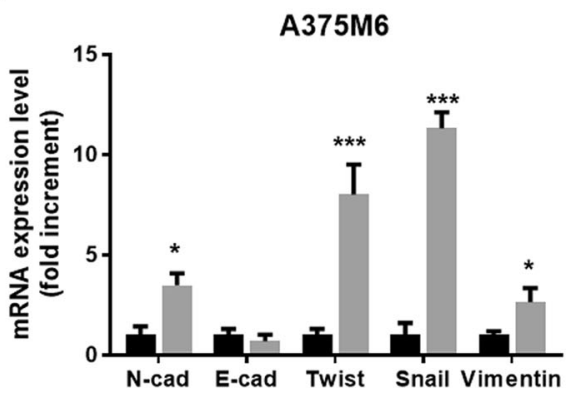

M21

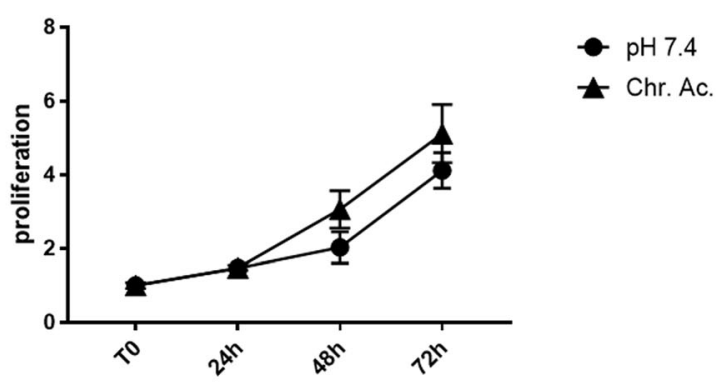

M21

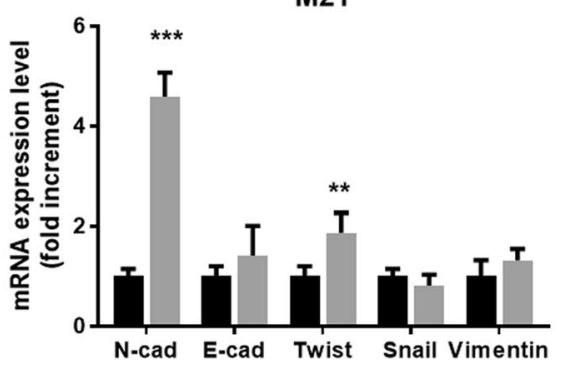

C

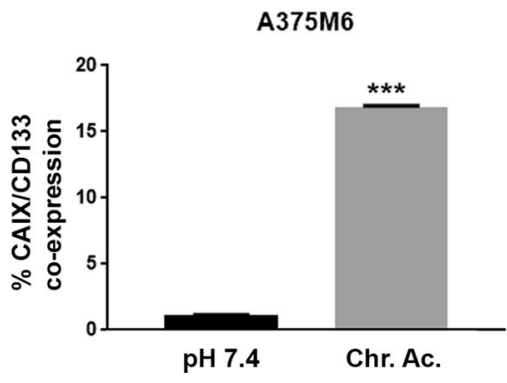

M21

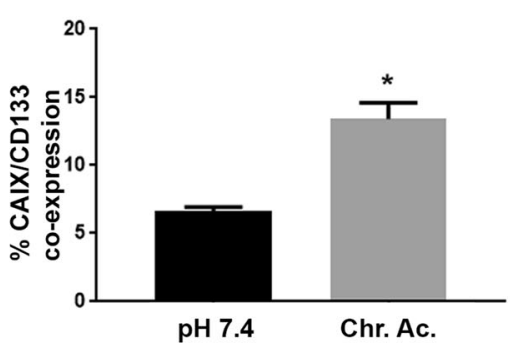

d

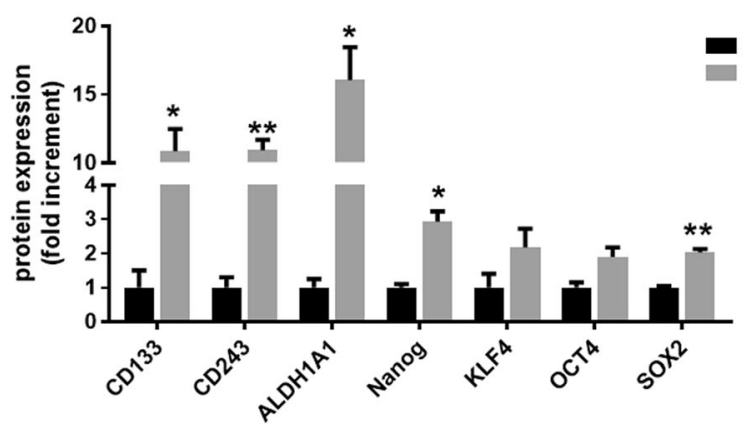

$\mathrm{A} 375 \mathrm{M} 6 \mathrm{pH} 7.4$

A375M6 Chr. Ac.

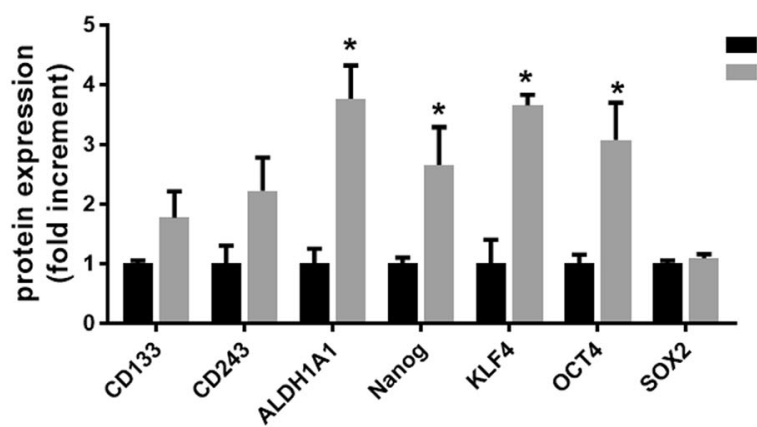

Fig. 1 EMT- and stem-related markers of melanoma cells chronically exposed to extracellular acidosis. a Growth curves of acid-adapted (Chr.ac.) and control ( $\mathrm{pH} 7.4)$ A375M6 and M21 cells obtained by MTT assay. b Real-time PCR of EMT-related markers in acid-adapted and control A375M6 and M21 cells. c Flow cytometer analysis of CAIX

Interestingly, in both pH 7.4R A375M6 and M21 cells, we observed a clear reduction of ZEB1 and Snail (Fig. 3a), two EMT-activators that are also known as stemness mediators [36, 37]. By real-time PCR analysis, we observed a tendence of stem-related genes, that were found up- and CD133 co-expressing cells under standard and acidic conditions. d Flow cytometer analysis of stem-related markers in A375M6 and M21 cells exposed to extracellular acidosis compared with control. * $p<0.05$, $* * p<0.01, * * * p<0.001$, Two-way ANOVA Sidak's multiple comparisons test for $\mathbf{a}, \mathbf{b}$, and $\mathbf{d}$; $t$ test for $\mathbf{c}$

regulated in acid-adapted melanoma cells, to come back near to the control level, in particular SOX2 and Nanog in both A375M6 and M21 cells, OCT4 in only M21 cell line; on the contrary, KFL4 was not only maintained at high level as acid-adapted cells but was even increased in 
a
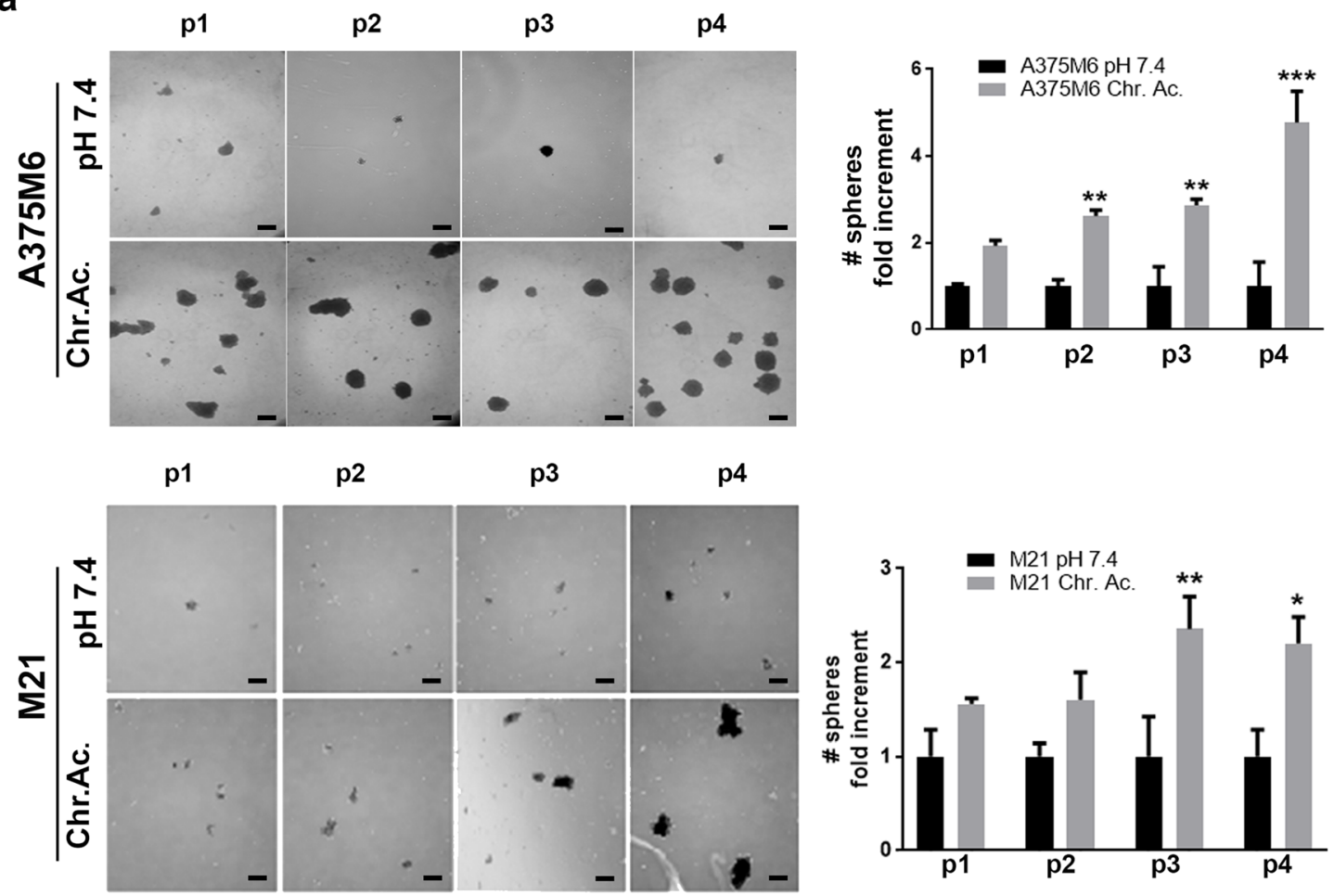

p2

p3

p4

b

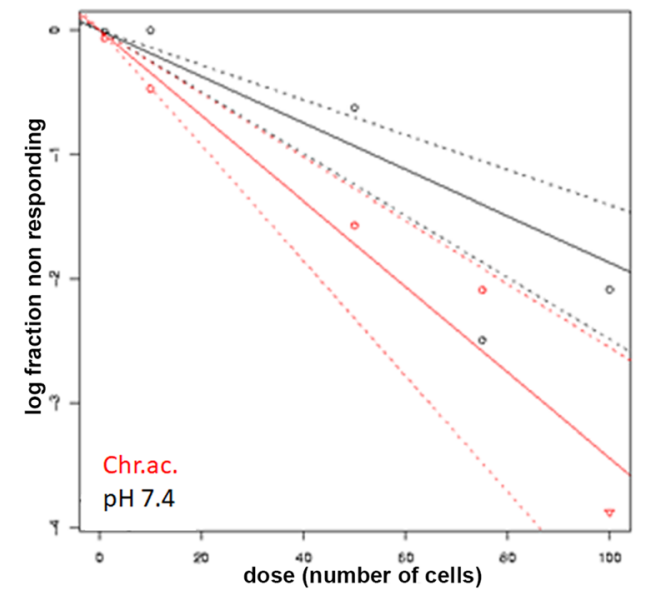

\begin{tabular}{|l|l|l|}
\hline & A375M6 pH 7.4 & A375M6 Chr. AC \\
\hline TIC (\%) & $1 / 53.3(1.87 \%)$ & $1 / 29(3.45 \%)$ \\
\hline $\mathbf{9 5 \%}$ Cl & $1 / 66-1 / 38$ & $1 / 39-1 / 22$ \\
\hline
\end{tabular}

Fig. 2 In vitro self-renewal ability of melanoma cells chronically exposed to extracellular acidosis. a Tumorsphere formation assay of A375M6 and M21 cells under chronic extracellular acidosis (Chr.ac.) and standard condition ( $\mathrm{pH}$ 7.4). Representative images (left) and relative quantification chart (right) of spheres from passage 1 to 4 (p1-p4). Scale bar: 200

both $\mathrm{pH}$ 7.4R cell lines (Fig. 3b). Moreover, the $\mathrm{pH} 7.4 \mathrm{R}$ melanoma cells showed a significantly reduced tumorsphere formation ability (Fig. 3c) and a decreased TIC percentage (Fig. 3d) compared with acid-adapted melanoma cells,

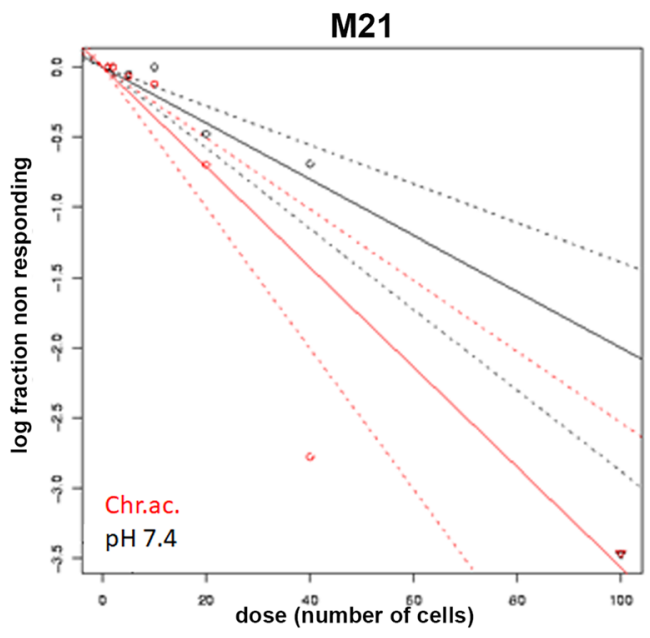

\begin{tabular}{|l|l|l|}
\hline & M21 pH 7.4 & M21 Chr. Ac \\
\hline TIC (\%) & $1 / 50(2.00 \%)$ & $1 / 29.7(3.37 \%)$ \\
\hline $\mathbf{9 5 \% ~ C l ~}$ & $1 / 72-1 / 34.7$ & $1 / 39.5-1 / 22.3$ \\
\hline
\end{tabular}

$\mu \mathrm{m}$. b Limiting dilution sphere assay of acid-adapted and control A375M6 and M21 cells. ELDA analysis plot (upper) and relative table reporting the TIC percentage (lower). * $p<0.05$, ** $p<0.01$, *** $p<$ 0.001, Two-way ANOVA, Sidak's multiple comparisons test

despite still increased compared with control cells. These data suggest that the stem-like phenotype of melanoma cells induced by acidosis is reversible, but 15 days is not enough to reach a complete phenotype reversion. 
a

pH 7.4 Chr.ac. pH 7.4R

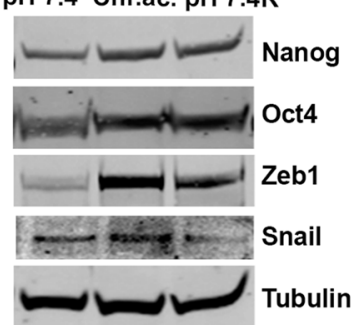

M21

pH 7.4 Chr.ac. pH 7.4R
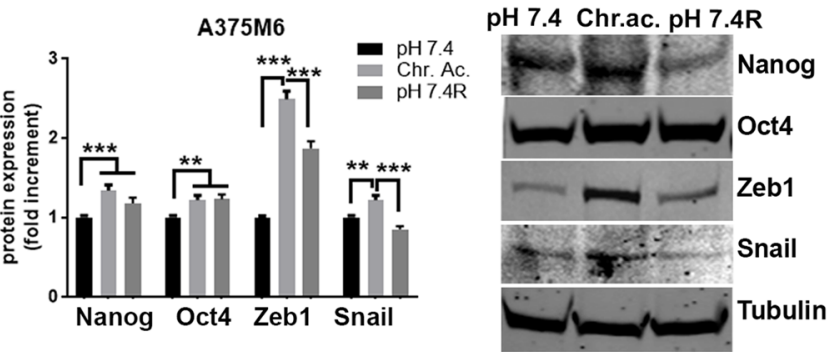

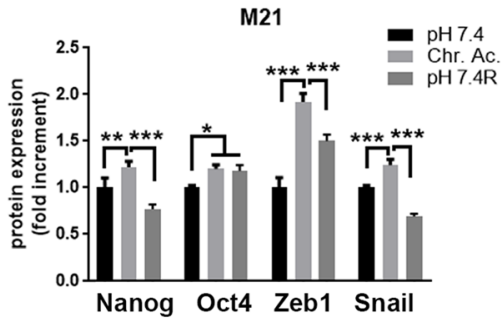

b
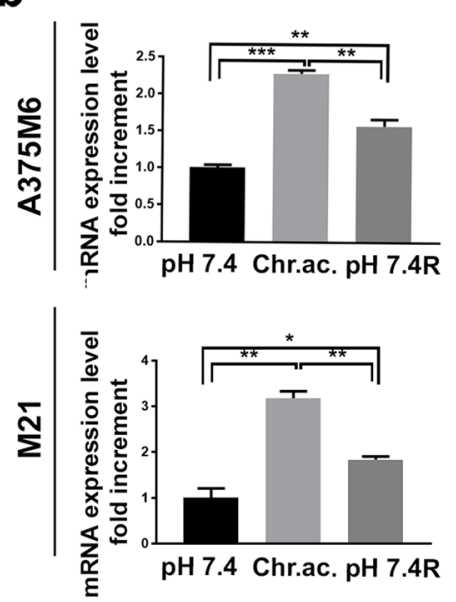

OCT4
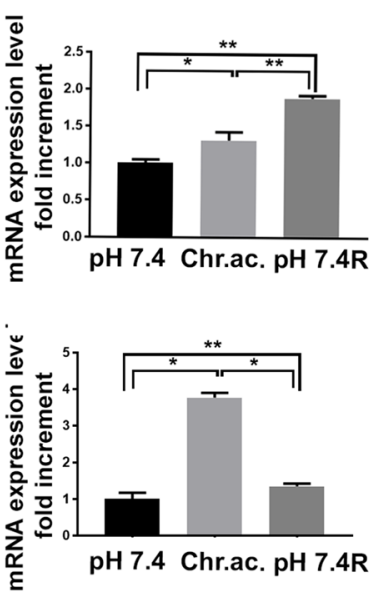

KLF4
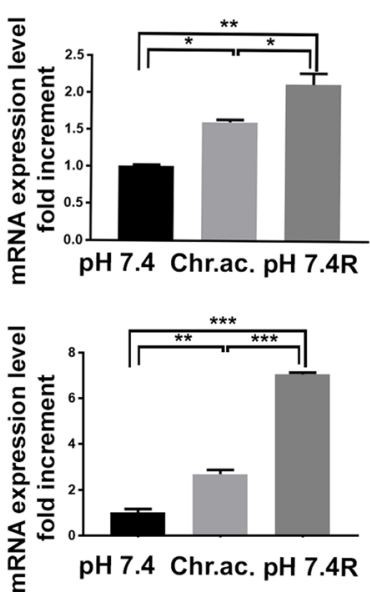

NANOG
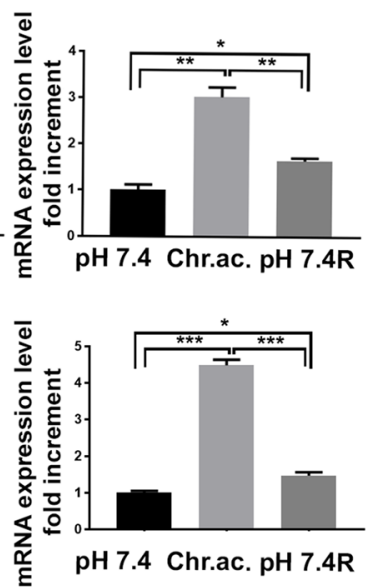

C
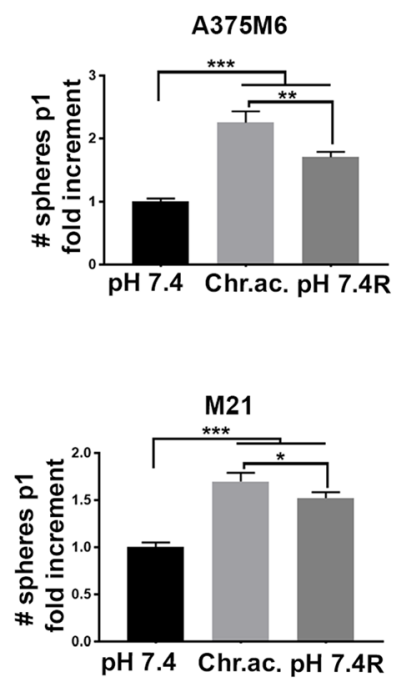

d

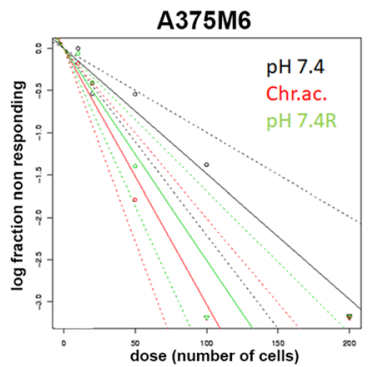

M21

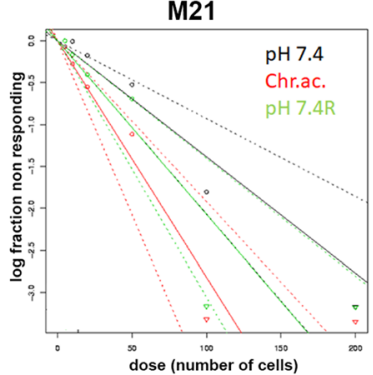

Fig. 3 The acidosis-induced stem-like phenotype is partially reversible by restoring standard $\mathrm{pH}$ condition. a WB analysis of EMT- and stemrelated markers in control ( $\mathrm{pH} 7.4$ ), acid-adapted (Chr.ac.), and $\mathrm{pH} 7.4$ restored (pH 7.4R) A375M6 and M21 cells. b Real-time PCR of stemrelated markers in control, acid-adapted, and $\mathrm{pH} 7.4$ restored A375M6

\begin{tabular}{|l|l|l|l|}
\hline & $\begin{array}{l}\text { A375M6 } \\
\text { pH 7.4 }\end{array}$ & $\begin{array}{l}\text { A375M6 } \\
\text { Chr.ac. }\end{array}$ & $\begin{array}{l}\text { A375M6 } \\
\text { pH 7.4R }\end{array}$ \\
\hline TIC (\%) & $1 / 67.4$ & $1 / 33.0$ & $1 / 39.9$ \\
& $(1.48 \%)$ & $(3.03 \%)$ & $(2.50 \%)$ \\
\hline $\mathbf{9 5 \% ~ C l ~}$ & $1 / 100.3-1 / 45.2$ & $1 / 49.8-1 / 21.9$ & $1 / 59.3-1 / 26.8$ \\
\hline
\end{tabular}

\begin{tabular}{|l|l|l|l|}
\hline & $\begin{array}{l}\text { M21 } \\
\text { pH 7.4 }\end{array}$ & $\begin{array}{l}\text { M21 } \\
\text { Chr.ac. }\end{array}$ & $\begin{array}{l}\text { M21 } \\
\text { pH 7.4R }\end{array}$ \\
\hline TIC (\%) & $\begin{array}{l}1 / 72.2 \\
(1.38 \%)\end{array}$ & $\begin{array}{l}1 / 35.5 \\
(2.81 \%)\end{array}$ & $\begin{array}{l}1 / 46.3 \\
(2.16 \%)\end{array}$ \\
\hline $\mathbf{9 5 \%} \mathbf{C l}$ & $1 / 107.7-1 / 48.4$ & $1 / 52.1-1 / 24.1$ & $1 / 71.3-1 / 32.7$ \\
\hline
\end{tabular}

and M21 cells. Tumorsphere formation (c) and limiting dilution sphere (d) assays of control, acid-adapted and $\mathrm{pH} 7.4$ restored A375M6 and M21 cells. $* p<0.05, * * p<0.01, * * * p<0.001$; two-way ANOVA, Sidak's multiple comparisons test for a; one-way ANOVA, Tukey's multiple comparisons test for $\mathbf{b}$ and $\mathbf{c}$ 


\section{EMT is required for the acquisition of the acidosis- induced stem-like phenotype in melanoma cells}

Since recent papers revealed the fundamental role of EMT in stemness induction [32], we wondered if the induction of an EMT phenotype in acid-adapted melanoma cells was required for the acquisition of stemness features. The NF-kB transcriptional factor is known to regulate EMT in different type of cancers $[38,39]$, and, in addition, we previously reported that it drives the acidosis-induced EMT in melanoma cells [25]. We thus decided to down-regulate acidosis-induced EMT by silencing the NF-kB coding gene RelA and observed, by western blot analysis, a clear reduction of the EMT markers NCadherin, Zeb1, Vimentin, and Slug (even though its reduction was not significant), and of the stem-related marker Nanog (Fig. 4a). The real-time PCR analysis confirmed the reduction in mRNA expression of the EMT markers NCadherin, Twist, Snail, and Vimentin and of the stem-related markers SOX2, OCT4, KFL4, and Nanog (Fig. 4b). Finally, the tumor sphere formation (Fig. 4c) and the in vitro limiting dilution (Fig. 4d) assays, respectively, showed a reduced melanosphere formation and a decreased TIC percentage in both the cell lines tested. These data suggest that the EMT program is required for the acquisition of a stem-like phenotype by acid-adapted melanoma cells.

\section{Melanoma cells adapted to extracellular acidosis show higher tumor-initiating potential than control cells}

Tumor-initiation ability in vivo was tested by subcutaneously injecting in CD-1 nude mice a low number of standard and acid-adapted A375M6 and M21 melanoma cells and allowed to generate tumor masses. By injecting $10^{2}$ acid-adapted A375M6 (Fig. 5a), nodules developed in higher number and earlier compared with control (5/6 tumors at day 18 vs $2 / 6$ tumors at day 27, respectively), and also increased in tumor volume (Fig. 3a, left panel). The ELDA analysis indicated that acid-adapted group contains higher percentage of TIC than control ( $0.40 \%$ vs $0.15 \%$, respectively) (Fig. 5a, right panel). By injecting $10^{3}$ A375M6 cells, no significant differences were observed between control and acid-adapted group (4/6 tumors at day 20 vs $5 / 6$ tumors at day 22 , respectively; data not shown), suggesting that acid-adapted A375M6 melanoma cells contain an expanded TIC subpopulation emerging when using a low number of cancer cells.

Thereafter, injecting $10^{2}$ control or acid-adapted M21 melanoma cells, a similar and very low incidence was obtained (1/6 tumors of both groups), although latency (day 50 for acidadapted vs day 60 for control group) and tumor volume evaluation indicated a more effectiveness of acid-adapted cells than control (data not shown). Increasing the number of injected M21 cells up to $10^{3}$, significant differences between the two groups have been observed in terms of incidence ( $4 / 6$ tumors for acid-adapted vs 1/6 tumors for control group), latency (day 28 for acid-adapted vs day 54 for control group), and tumor volume (Fig. 5b, left panel). The ELDA analysis (Fig. 5b, right panel) clearly showed that the percentage of TIC of acid-adapted group is higher than in control one ( $0.12 \%$ vs $0.03 \%$, respectively).

\section{Chronic acidosis adaptation induces high plasticity and trans-differentiation ability in melanoma cells}

A different way to test in vitro stemness of tumor cells is to evaluate their ability to trans-differentiate in other cellular types when subjected to specific differentiating stimuli. To this aim, standard and acid-adapted melanoma cells were cultured for 3 weeks under pro-adipogenic- or pro-osteogenicdifferentiating media and then evaluated by molecular and histological techniques. We firstly checked by flow cytometry their intrinsic predisposition to express the CD105, CD73, and CD90 mesenchymal stem cell markers, and the CD34 hematopoietic stem cell marker was used as negative control, observing that chronic acidosis increased the expression of CD105, CD73, and CD90 in A375M6 and CD105 in M21 cells compared with control cells (Fig. 6a). Treating melanoma cells for 3 weeks with pro-adipogenic-differentiating medium, we observed a higher trans-differentiation ability of acid-adapted cells compared with control cells, assessed via qPCR analysis of the adipogenic markers LPL, CEBP $\alpha$, and PPAR $\gamma$, and via Oil Red O staining of intracytoplasmic lipid drops (Fig. 6b). In parallel, we observed that the proosteogenic-differentiating medium induces a stronger positivity for the Alizarin Red staining in acid-adapted melanoma cells compared with control cells, despite at a molecular level only ALPL (for A375M6 and M21 cells) and SOST (for M21 cells) genes were significantly increased in acidic-adapted cells (Fig. 6c). These findings disclose the ability of acidadapted A375M6 and M21 melanoma cells to easily transdifferentiate towards mesoderm-derived lineages upon specific stimuli.

\section{Extracellular acidosis promotes a stem-like phenotype in prostate and colorectal carcinoma cells}

To verify whether a chronic low $\mathrm{pH}$ might be also able to extend the stem-cell subpopulation not only in melanoma but also in other tumor types, we evaluated some aspects of CSC in prostate and colorectal adenocarcinoma cell lines, PC3 and HCT116, respectively, chronically exposed to an acidic medium compared with control. First of all, we observed that acid-adapted prostate and colon cancer cells, compared with control, express higher protein levels of stem-related markers (Fig. 7a). Moreover, limiting dilution analysis shows that acid-adapted PC3 and HCT116 cells display an increased self-renewal 
a

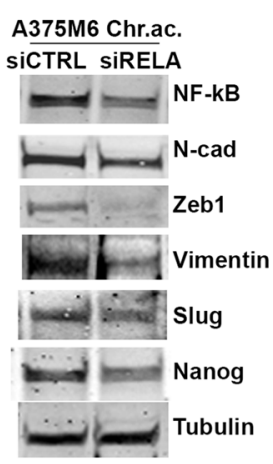

M21 Chr.ac.

siCTRL SIRELA
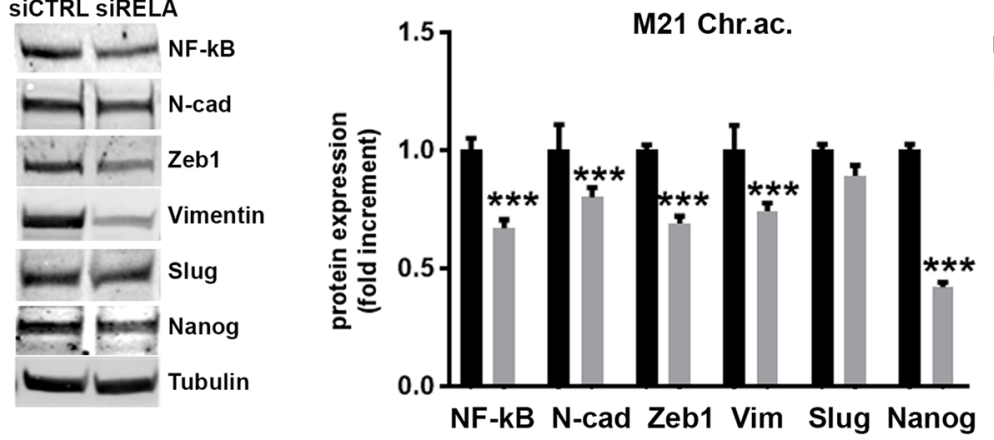

A375M6 Chr.ac.

SICTRL

SiRELA

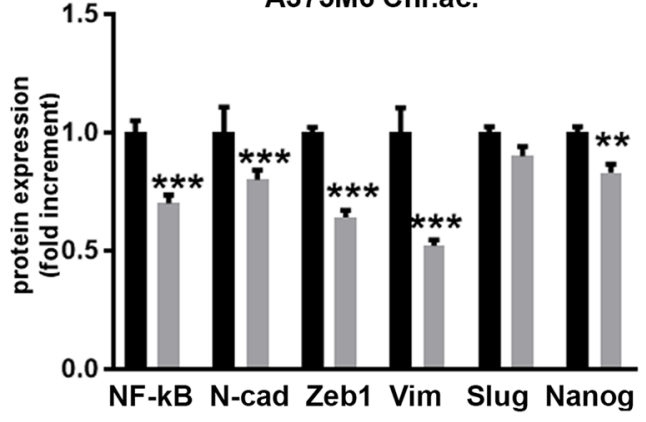

siCTRL

siRELA

b

A375M6 Chr.ac.

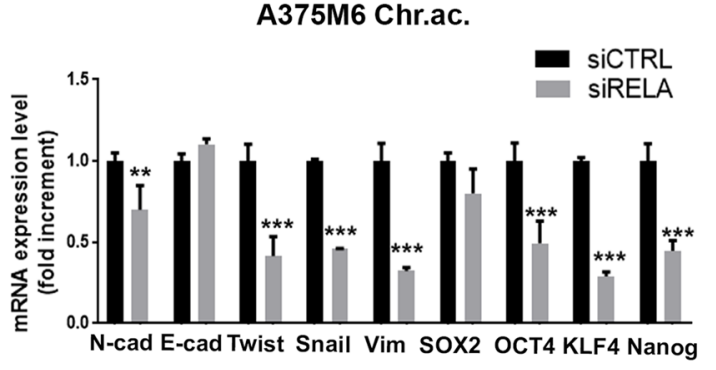

M21 Chr.ac.

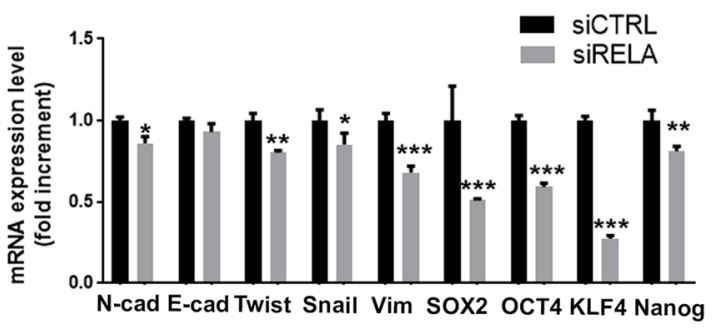

C
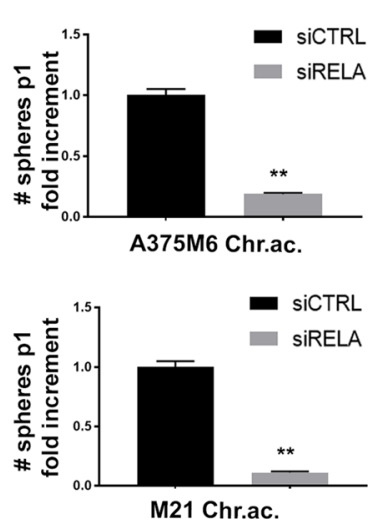

d

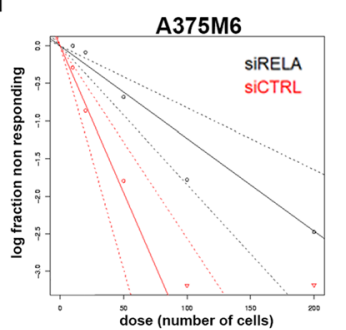

\begin{tabular}{|l|l|l|}
\hline & $\begin{array}{l}\text { A375M6 Chr.ac. } \\
\text { siCTRL }\end{array}$ & $\begin{array}{l}\text { A375M6 Chr. Ac } \\
\text { siRELA }\end{array}$ \\
\hline TIC (\%) & $1 / 25.6(3.90 \%)$ & $1 / 81.2(1.23 \%)$ \\
\hline $95 \% \mathrm{Cl}$ & $1 / 39.1-1 / 16.8$ & $1 / 121.5-1 / 54.2$ \\
\hline
\end{tabular}

M21

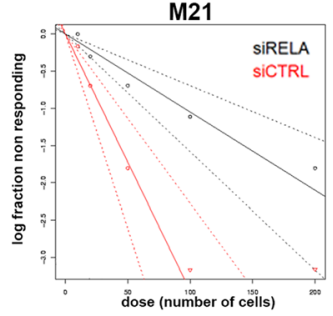

\begin{tabular}{|l|l|l|}
\hline & $\begin{array}{l}\text { M21 Chr.ac. } \\
\text { siCTRL }\end{array}$ & $\begin{array}{l}\text { M21 Chr. Ac } \\
\text { siRELA }\end{array}$ \\
\hline TIC (\%) & $1 / 29(3.44 \%)$ & $1 / 95.2(1.01 \%)$ \\
\hline $95 \% \mathrm{Cl}$ & $1 / 44-1 / 19.1$ & $1 / 144-1 / 63.1$ \\
\hline
\end{tabular}

Fig. 4 EMT down-regulation via RELA silencing in acid-adapted melanoma cells reduces the stem-like phenotype. WB (a) and real-time PCR (b) analysis of EMT- and stem-related markers in siCTRL and siRELA acid-adapted A375M6 and M21 cells. Tumorsphere formation (c) and limiting dilution sphere (d) assays of siCTRL and siRELA acid-adapted A375M6 and M21 cells. ${ }^{*} p<0.05, * * p<0.01,{ }^{* * *} p<0.001$; two-way ANOVA, Sidak's multiple comparisons test for $\mathbf{a}$ and $\mathbf{b} ; t$ test for $\mathbf{c}$ 

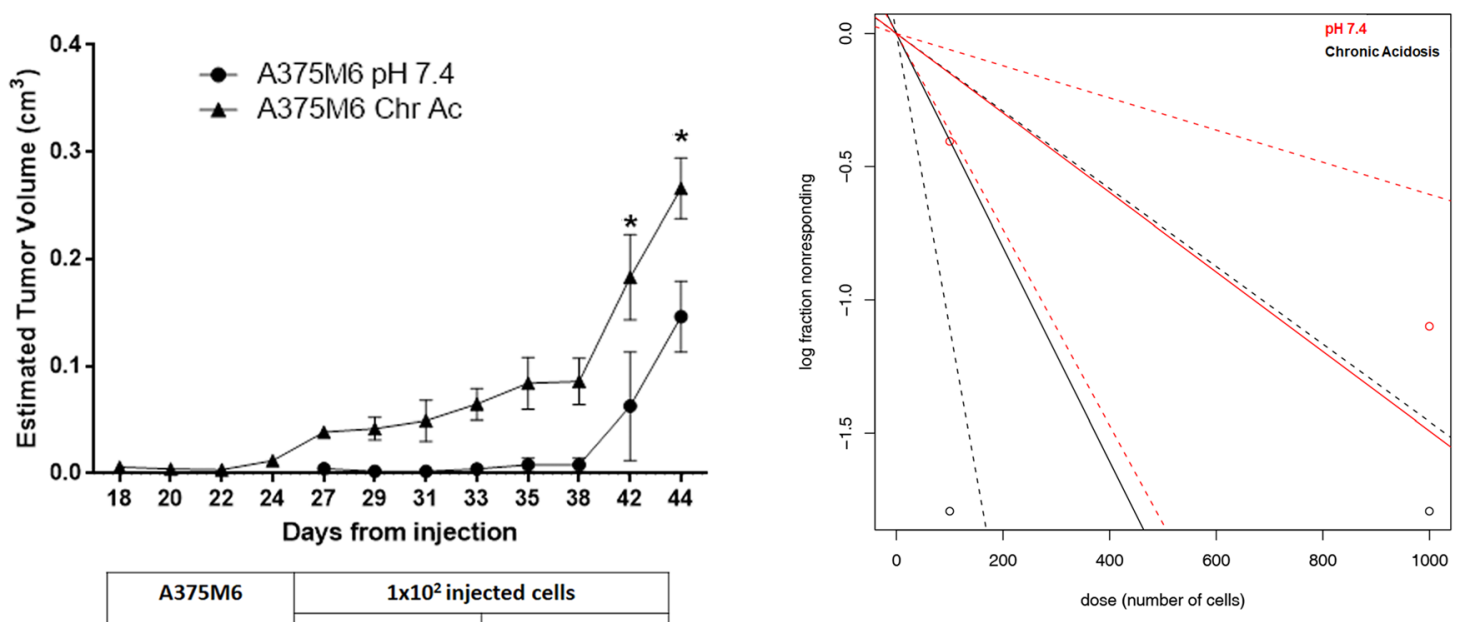

\begin{tabular}{|l|l|l|}
\hline \multirow{2}{*}{ A375M6 } & \multicolumn{2}{c|}{$1 \times 10^{2}$ injected cells } \\
\cline { 2 - 3 } & \multicolumn{1}{|c|}{$\mathrm{pH} \mathrm{7.4}$} & Chronic Acidosis \\
\hline Incidence & $2 / 6$ & $5 / 6$ \\
\hline Latency & day 27 & day 18 \\
\hline Volume $\left(\mathrm{cm}^{3}\right)$ & $\begin{array}{l}0,146 \pm 0,047 \\
\text { (day 44) }\end{array}$ & $\begin{array}{l}0,265 \pm 0,057 \\
\text { (day 44) }\end{array}$ \\
\hline
\end{tabular}

\begin{tabular}{|l|l|l|}
\hline A375M6 & pH 7.4 & Chronic Acidosis \\
\hline TIC (\%) & $1 / 670(0.15 \%)$ & $1 / 249(0.40 \%)$ \\
\hline $95 \% \mathrm{Cl}$ & $1 / 271.8-1 / 1653$ & $1 / 90.6-1 / 686$ \\
\hline
\end{tabular}

\section{b}

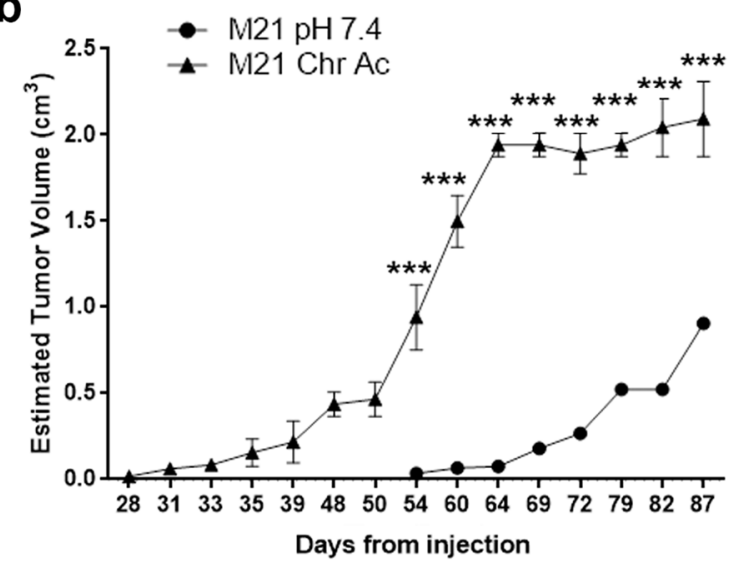

\begin{tabular}{|l|l|l|}
\hline \multirow{2}{*}{ M21 } & \multicolumn{2}{c|}{$1 \times 10^{3}$ injected cells } \\
\cline { 2 - 3 } & \multicolumn{1}{|c|}{ pH 7.4 } & Chronic Acidosis \\
\hline Incidence & $1 / 6$ & $4 / 6$ \\
\hline Latency & day 54 & day 28 \\
\hline Volume $\left(\mathrm{cm}^{3}\right)$ & $\begin{array}{l}0,805 \pm 0,141 \\
\text { (day } 87)\end{array}$ & $\begin{array}{l}2,093 \pm 0,306 \\
\text { (day } 87)\end{array}$ \\
\hline
\end{tabular}

Fig. 5 Extracellular acidosis increases in vivo tumor initiation and growth of melanoma cells. In vivo tumor growth (left) and estimated tumor-initiation frequency (ELDA software) (right) after subcutaneous injection in CD-1 mice of either 100 acid-adapted (Chr.ac.) or standard

potential, suggested by the higher sphere frequency and the TIC percentage obtained by ELDA analysis (Fig. 7b). In line with these results, acid-adapted PC3 and HCT116 cells also gave rise to higher number of tumorspheres compared with control (Fig. $7 \mathrm{c}$ ), highlighting the possibility that acidosis promotion of stemness is a more general phenomenon that could be extended to different tumor types.

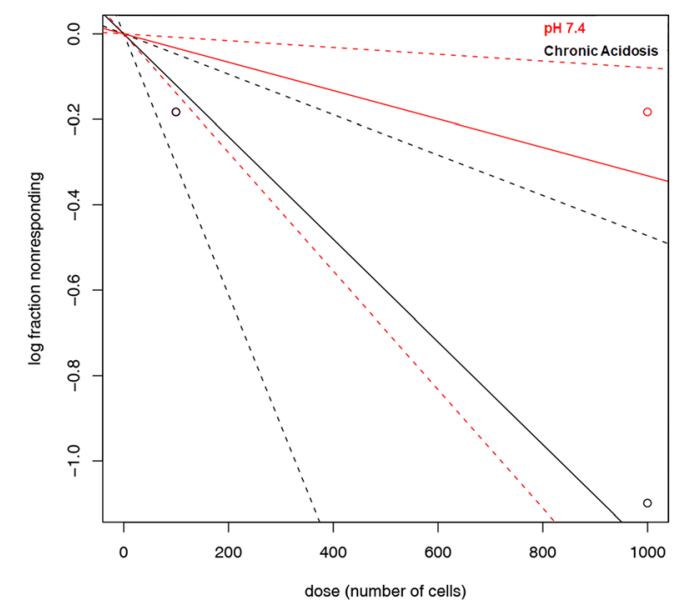

\begin{tabular}{|l|l|l|}
\hline M21 & pH 7.4 & Chronic Acidosis \\
\hline TIC (\%) & $1 / 3012(0.03 \%)$ & $1 / 832(0.12 \%)$ \\
\hline $95 \% \mathrm{Cl}$ & $1 / 720-1 / 12595$ & $1 / 327-1 / 2116$ \\
\hline
\end{tabular}

(pH 7.4) A375M6 cells (a) or 1000 acid-adapted or standard M21 cells (b). $* * p<0.01, * * * p<0.001$; two-way ANOVA, Sidak's multiple comparisons test ( $\mathrm{pH} 7.4 \mathrm{vs} \mathrm{Chr}$.ac. for each time point)

\section{Discussion}

Many types of cancer display subpopulations of CSC, that share features with physiological stem cells (i.e., self-renewal, differentiation, indefinite proliferation abilities) through which they cause tumor progression [40-42]. CSC are protected and maintained in a well- 
a

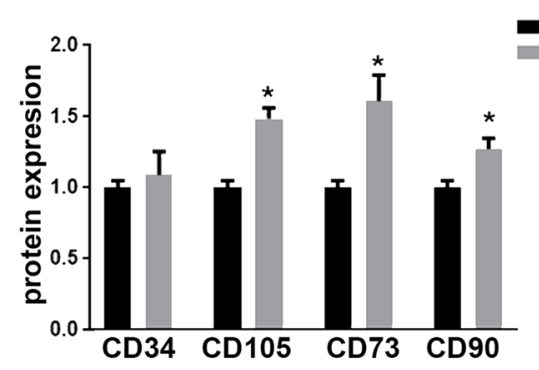

b
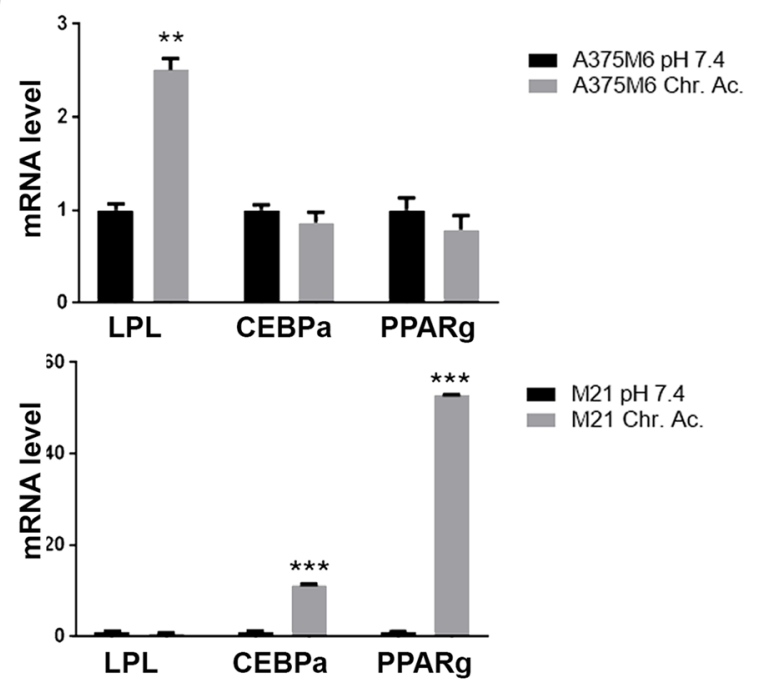

C
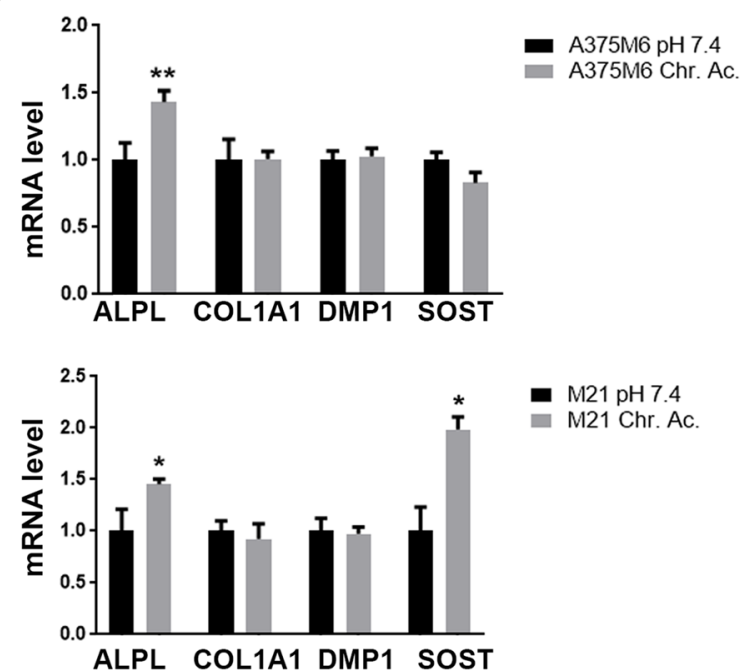

Fig. 6 Chronic acidosis adaptation induces high plasticity and transdifferentiation ability in melanoma cells. a Flow cytometer analysis for the expression of the mesenchymal markers CD105, CD73, and CD90 in acid-adapted (Chr.ac.) A375M6 and M21 compared with relative control. CD34 used as negative control. b Real-time PCR analysis for adipogenic differentiation markers LPL, CEBP $\alpha$, and PPAR $\gamma$ (left) and representative pictures of Oil Red O lipid drop staining (right) in acid-adapted

defined microenvironment providing a permissive niche able to enforce their survival ability and aggressive

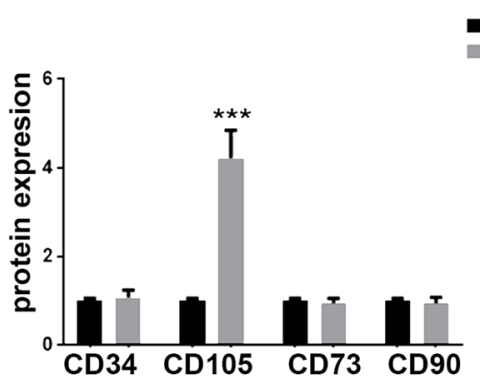

M21 pH 7.4 M21 Chr. Ac.
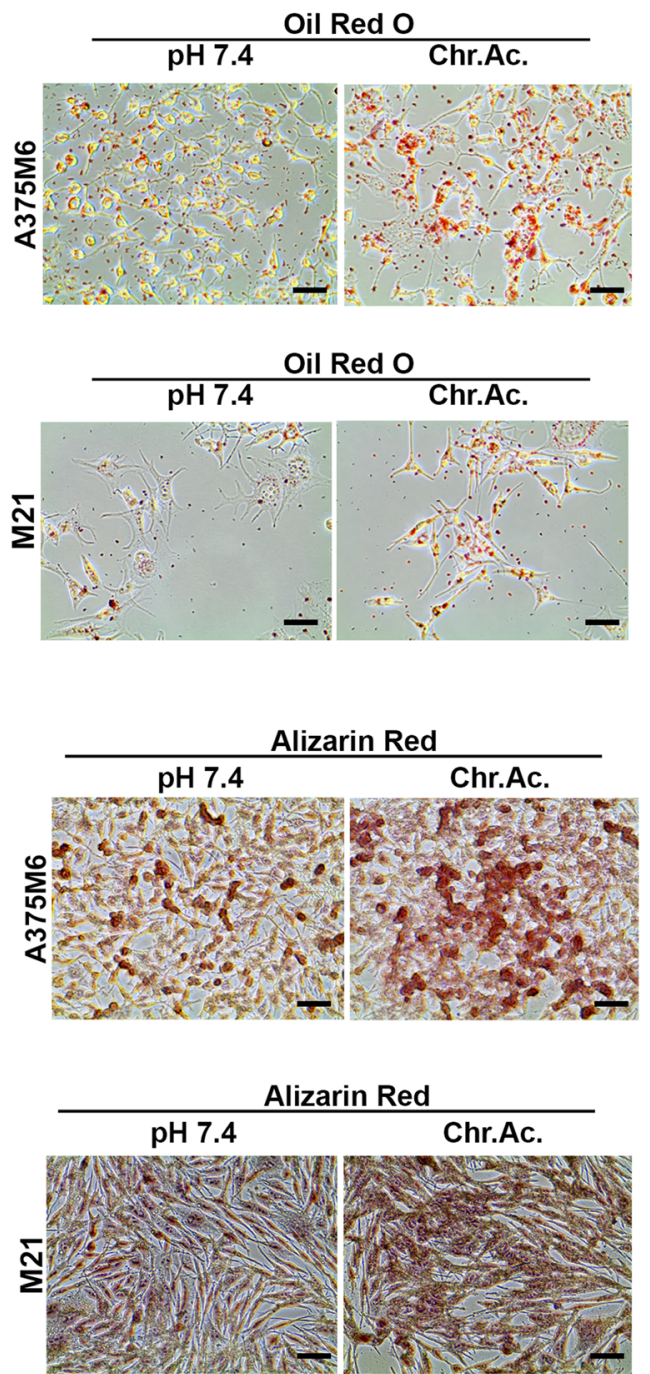

A375M6 and M21 compared with control cells. $\mathbf{c}$ Real-time PCR analysis for osteogenic differentiation markers ALPL, COL1A1, DMP1, and SOST (left) and representative pictures of Alizarin Red calcium phosphate deposit staining (right) in acid-adapted A375M6 and M21 compared with control cells. Scale bar: $50 \mu \mathrm{m} . * p<0.05, * * p<0.01, * * * p$ $<0.001$; two-way ANOVA, Sidak's multiple comparisons test

properties [43]. Alongside hypoxia, that plays an important role in stemness [44], extracellular acidosis might 
Fig. 7 Stem-like features of prostate and colorectal cancer cells chronically exposed to extracellular acidosis. a Flow cytometer analysis for stemrelated markers in $\mathrm{PC} 3$ prostate and HCT116 colorectal cancer cells exposed to chronic acidosis (Chr.ac.) compared with control (pH 7.4). b Limiting dilution sphere assay of acid-adapted and control PC 3 and HCT116 cells. ELDA analysis plot (upper panel) and relative TIC percentage value (lower panel). c Tumorsphere formation assay of $\mathrm{PC} 3$ and HCT116 cells under chronic extracellular acidosis and standard condition $* p<0.05, * * p<0.01$, $* * * p<0.001$; two-way ANOVA, Sidak's multiple comparisons test. a
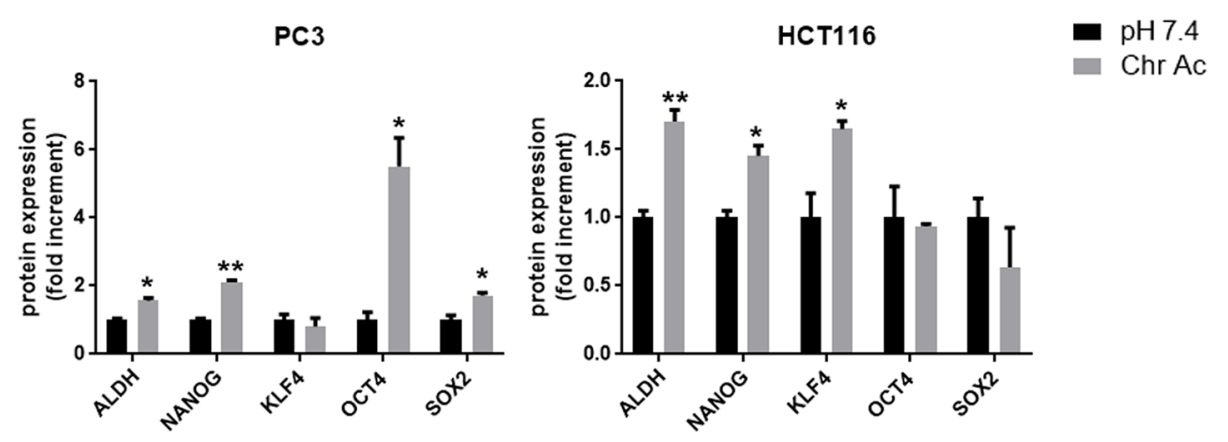

b
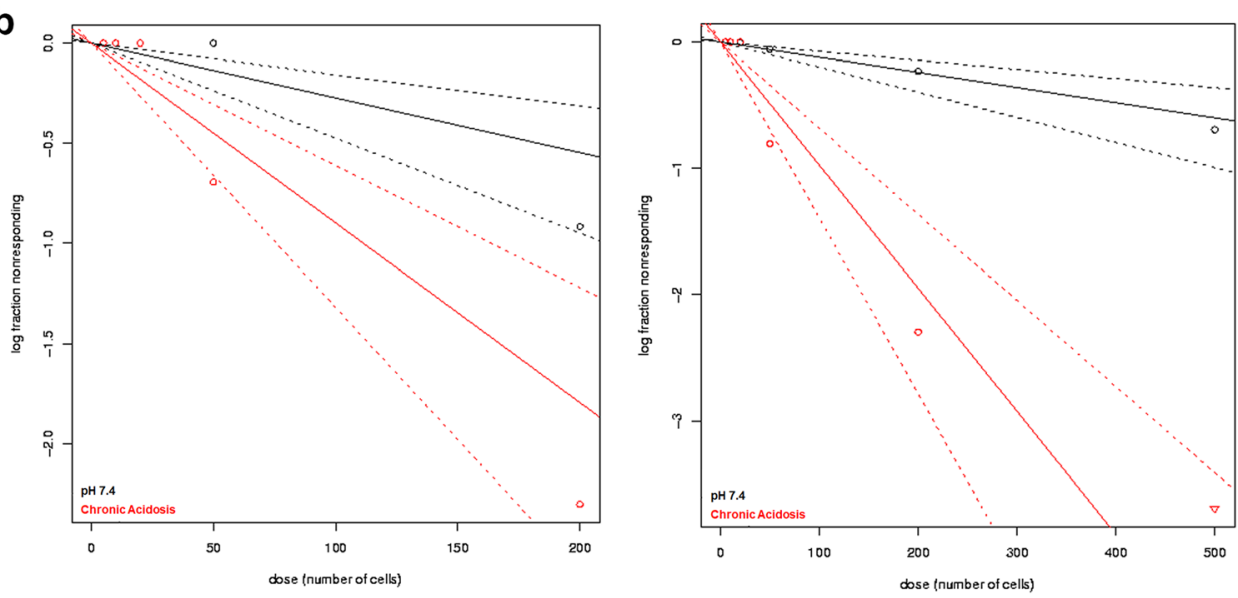

\begin{tabular}{|l|l|l|}
\hline & PC3 & PC3 Chr. Ac \\
\hline TIC (\%) & $1 / 366(2,7 \%)$ & $1 / 111(9,0 \%)$ \\
\hline $\mathbf{9 5 \%}$ Cl & $1 / 635-1 / 210,9$ & $1 / 163-1 / 75,8$ \\
\hline
\end{tabular}

\begin{tabular}{|l|l|l|}
\hline & HCT116 & HCT116 Chr. AC \\
\hline TIC (\%) & $1 / 834(1,1 \%)$ & $1 / 103(9,7 \%)$ \\
\hline $\mathbf{9 5 \%} \mathrm{Cl}$ & $1 / 1384-1 / 502,7$ & $1 / 147-1 / 71,8$ \\
\hline
\end{tabular}

C

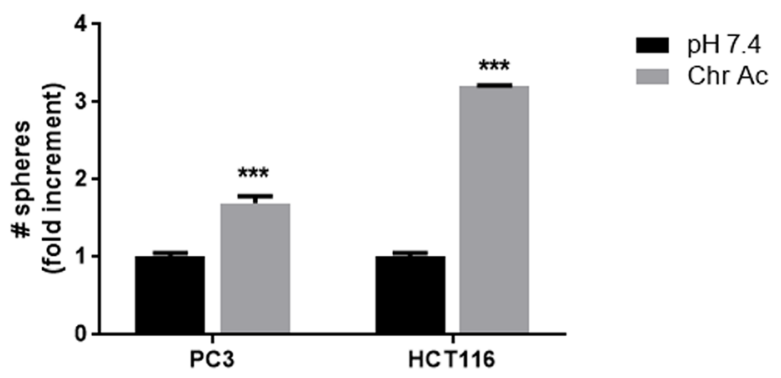

represent another crucial characteristic of tumor microenvironment able to influence stemness of cancer cells.

We collected a wide number of evidences inevitably linking a possible association between chronic extracellular acidosis and the promotion of a stem-like phenotype in melanoma cells.

Notably, EMT, apoptosis resistance, anoikis, and drug resistance features, we already observed under acidic conditions, have been linked to a tumor profile with successful metastatic dissemination $[6,45,46]$. Here we demonstrate that a higher number of acid-adapted melanoma cells co-express CAIX and CD133 proteins compared with control, a further indication of acidosis-induced stemness. Indeed, CAIX expression has been correlated with stem cell niches in normal tissues [47] and considered a critical mediator of the selfrenewal and invasive potential of cancer cells by regulating the transcription of EMT- and stemness-related genes [33, 48].

Here we show the induction of the self-renewal and pluripotency markers Nanog, KLF4, OCT4, and SOX2 and the over-expression of the CSC markers CD133, CD243, and ALDH1A1 in melanoma cells exposed to chronic acidosis compared with control cells. In line with our results, acidosis has been associated with the increased CSC-marker expression in prostate cancer [49] and malignant glioma [50, 51], 
osteosarcoma [52], and the maintenance of stemness in mesenchymal cells [53, 54]. Also, OCT-4 expression in murine fibroblasts increases as $\mathrm{pH}$ shifts from 7.4 to 6.5 [55].

We confirmed that extracellular acidosis induces the selfrenewal capability of cancer cells by the in vitro tumorsphere formation and limiting dilution assays. We found that acidadapted cells give a higher number of melanospheres with bigger size than control cells and preserve their stem-like phenotype for at least four passages, whereas control cells gradually lose their ability to form melanospheres. This effect is not limited to melanoma, but rather proved in PC3 prostate and HCT116 colon cancer cells, that indeed also showed high expression of stem-related proteins.

We also showed that the stem-like phenotype induced in melanoma cells by acidosis is a reversible phenomenon, as suggested by the reduced expression of stem-related markers and by the lower self-renewal capability of acid-adapted cells grown back for 15 days at standard $\mathrm{pH}$ medium, compared with acid-adapted cells. The phenotype we observed was not completely reverted at control level, but the phenomenon was clear enough to confirm that the acidosis-induced stem-like phenotype is dynamic and subjected to variations depending on environmental conditions, an evidence that contributes to define the increased plasticity and aggressiveness of acidadapted tumor cells [35].

Several studies have demonstrated the link between EMT and stemness in a variety of human carcinoma [32, 45], and recently, EMT with its mediators, such as Zeb1 [36], Snail [37], Slug [56], and NF-kB [57, 58], has been described as a key mechanism by which cells are conferred with stem-cell properties. Here, we demonstrated that the stem-like phenotype induced in acid-adapted melanoma cells is EMT-dependent, since by inhibiting the well-known EMT mediator NF$\mathrm{kB}$, the stem-like phenotype acquired by acid-adapted melanoma cells has clearly been reduced.

CSC are also denominated tumor-initiating cells (TIC) being responsible for the initiation, recurrence, and metastases of a tumor. For that, increased in vivo tumorigenicity is one of the hallmarks of CSC. Interestingly, melanoma TIC population has been demonstrated to depend on SOX2 expression [59], that we found up-regulated under acidic conditions [20]. The in vivo evaluation of the tumor-initiation ability of acidadapted melanoma cells compared with control showed that chronic acidosis induces the earlier development of a higher number of tumors compared with the standard $\mathrm{pH}$ condition, and the ELDA statistical analysis revealed a higher percentage of TIC in acid-adapted group than control. Some evidences showed that increasing the extracellular $\mathrm{pH}$ reduces tumor growth, prevents cancer invasion [26, 60], and restores drug sensitivity [61]. Recently acidosis has been proposed as potential therapeutic target to eradicate CSC [62].

Another hallmark of CSC is the multi-lineage differentiation plasticity that influences tumor progression and drug resistance [63]. Based on the origin of melanoma, we thought that the melanoma CSC should potentially differentiate into mesenchymal cell types, such as adipocytes and osteoblastlike cells. By treating melanoma cells with appropriate differentiating media, we observed that acid-adapted melanoma cells, compared with control, show higher ability to transdifferentiate in adipocyte and osteoblast-like cells. A recent study showed that a continuous exposure to low $\mathrm{pHe}$ for 21 days of bone marrow stem cells and dental pulp stem cells impairs the osteogenic differentiation of both cell types [53], suggesting that extracellular acidosis is crucial for the maintenance of a de-differentiated state.

To conclude, our results provide evidences that acidity leads to a reprogramming of a very plastic tumor phenotype toward the expression of stem-related markers, high clonogenic, and trans-differentiating ability. This could clarify the reasons why extracellular acidosis is able to promote aggressive traits in cancer, dramatically contributing to tumor progression and metastatic disease. Thus, acidosis needs to be considered a new and specific cue of stem cell niche, able to offer an innovative target for cancer therapy.

Acknowledgements Open access funding provided by Università degli Studi di Firenze within the CRUI-CARE Agreement.

Author contributions Silvia Peppicelli: Conceptualization, Investigation, Formal analysis, Writing-Original Draft, Visualization, Project administration.

Elena Andreucci: Conceptualization, Investigation, Formal analysis, Writing-Original Draft, Visualization, Project administration. Jessica Ruzzolini: Validation, Formal analysis, Visualization.

Francesca Bianchini: Investigation, Visualization, Writing-Review and editing.

Alessio Biagioni: Validation, Formal analysis, Visualization.

Laura Papucci: Investigation, Formal analysis.

Lucia Magnelli: Investigation, Formal analysis.

Benedetta Mazzanti: Methodology, Resources.

Barbara Stecca: Methodology, Investigation, Writing-Review and editing.

Lido Calorini: Resources, Writing-Original Draft, Supervision, Funding acquisition.

Funding information This study was financially supported by Istituto Toscano Tumori. Elena Andreucci and Alessio Biagioni were supported by a AIRC fellowship for Italy.

\section{Compliance with ethical standards}

Conflicts of interest The authors declare that they have no conflict of interest.

Open Access This article is licensed under a Creative Commons Attribution 4.0 International License, which permits use, sharing, adaptation, distribution and reproduction in any medium or format, as long as you give appropriate credit to the original author(s) and the source, provide a link to the Creative Commons licence, and indicate if changes were made. The images or other third party material in this article are included in the article's Creative Commons licence, unless indicated otherwise in a credit line to the material. If material is not included in the article's 
Creative Commons licence and your intended use is not permitted by statutory regulation or exceeds the permitted use, you will need to obtain permission directly from the copyright holder. To view a copy of this licence, visit http://creativecommons.org/licenses/by/4.0/.

\section{References}

1. Peitzsch C, Tyutyunnykova A, Pantel K, Dubrovska A (2017) Cancer stem cells: the root of tumor recurrence and metastases. Semin Cancer Biol 44:10-24

2. Seftor EA, Margaryan NV, Seftor REB, Hendrix MJC (2019) Heterogeneity of Melanoma with Stem Cell Properties. Adv Exp Med Biol 1139:105-114

3. Siegel R, Ma J, Zou Z, Jemal A (2014) Cancer statistics, 2014. CA Cancer J Clin. 64:9-29

4. Fang D, Nguyen TK, Leishear K, Finko R, Kulp AN, Hotz S, van Belle PA, Xu X, Elder DE, Herlyn M (2005) A tumorigenic subpopulation with stem cell properties in melanomas. Cancer Res 65: 9328-9337

5. Anurag C, Singh N, Vipin Kumar G, Verma M (2019) Vasculogenic Mimicry and Its Role in Cancer. Am J Pharmacol 2:1013

6. Schatton T, Frank MH (2008) Cancer stem cells and human malignant melanoma. Pigment Cell Melanoma Res 21:39-55

7. Quintana E, Shackleton M, Sabel MS, Fullen DR, Johnson TM, Morrison SJ (2008) Efficient tumour formation by single human melanoma cells. Nature. 456:593-598

8. Postovit L-M, Seftor EA, Seftor REB, Hendrix MJC (2006) Influence of the microenvironment on melanoma cell fate determination and phenotype. Cancer Res 66:7833-7836

9. Webb BA, Chimenti M, Jacobson MP, Barber DL (2011) Dysregulated $\mathrm{pH}$ : a perfect storm for cancer progression. Nat Rev Cancer 11:671-677

10. Peppicelli S, Andreucci E, Ruzzolini J, Laurenzana A, Margheri F, Fibbi G, del Rosso M, Bianchini F, Calorini L (2017) The acidic microenvironment as a possible niche of dormant tumor cells. Cell Mol Life Sci. 74:2761-2771

11. Peppicelli S, Ruzzolini J, Bianchini F, Andreucci E, Nediani C, Laurenzana A et al (2019) Anoikis resistance as a further trait of acidic-adapted melanoma cells. J Oncol. 2019:8340926

12. Ruzzolini J, Peppicelli S, Andreucci E, Bianchini F, Margheri F, Laurenzana A, Fibbi G, Pimpinelli N, Calorini L (2017) Everolimus selectively targets vemurafenib resistant BRAFV600E melanoma cells adapted to low $\mathrm{pH}$. Cancer Lett 408:43-54

13. Muz B, de la Puente P, Azab F, Azab AK (2015) The role of hypoxia in cancer progression, angiogenesis, metastasis, and resistance to therapy. Hypoxia (Auckl) 3:83-92

14. Vander Heiden MG, Cantley LC, Thompson CB (2009) Understanding the Warburg effect: the metabolic requirements of cell proliferation. Science. 324:1029-1033

15. Mookerjee SA, Goncalves RLS, Gerencser AA, Nicholls DG, Brand MD (2015) The contributions of respiration and glycolysis to extracellular acid production. Biochim Biophys Acta 1847:171181

16. Reshetnyak YK, Yao L, Zheng S, Kuznetsov S, Engelman DM, Andreev OA (2011) Measuring tumor aggressiveness and targeting metastatic lesions with fluorescent pHLIP. Mol Imaging Biol 13: $1146-1156$

17. Vaupel P (2004) Tumor microenvironmental physiology and its implications for radiation oncology. Semin Radiat Oncol 14:198206
18. Damaghi M, Gillies R (2017) Phenotypic changes of acid-adapted cancer cells push them toward aggressiveness in their evolution in the tumor microenvironment. Cell Cycle 16:1739-1743

19. Pillai SR, Damaghi M, Marunaka Y, Spugnini EP, Fais S, Gillies RJ (2019) Causes, consequences, and therapy of tumors acidosis. Cancer Metastasis Rev 38:205-222

20. Andreucci E, Pietrobono S, Peppicelli S, Ruzzolini J, Bianchini F, Biagioni A, Stecca B, Calorini L (2018) SOX2 as a novel contributor of oxidative metabolism in melanoma cells. Cell Commun Signal 16:87

21. Andreucci E, Peppicelli S, Carta F, Brisotto G, Biscontin E, Ruzzolini J, Bianchini F, Biagioni A, Supuran CT, Calorini L (2017) Carbonic anhydrase IX inhibition affects viability of cancer cells adapted to extracellular acidosis. J Mol Med 95:1341-1353

22. Riemann A, Rauschner M, Gießelmann M, Reime S, Haupt V, Thews O (2019) Extracellular acidosis modulates the expression of epithelial-mesenchymal transition (EMT) markers and adhesion of epithelial and tumor cells. Neoplasia 21:450-458

23. Suzuki A, Maeda T, Baba Y, Shimamura K, Kato Y (2014) Acidic extracellular $\mathrm{pH}$ promotes epithelial mesenchymal transition in Lewis lung carcinoma model. Cancer Cell Int 14:129

24. Zhu S, Zhou HY, Deng SC, Deng SJ, He C, Li X, Chen JY, Jin Y, Hu ZL, Wang F, Wang CY, Zhao G (2017) ASIC1 and ASIC3 contribute to acidity-induced EMT of pancreatic cancer through activating Ca2+/RhoA pathway. Cell Death Dis 8:e2806

25. Peppicelli S, Bianchini F, Torre E, Calorini L (2014) Contribution of acidic melanoma cells undergoing epithelial-to-mesenchymal transition to aggressiveness of non-acidic melanoma cells. Clin Exp Metastasis 31:423-433

26. Estrella V, Chen T, Lloyd M, Wojtkowiak J, Cornnell HH, IbrahimHashim A, Bailey K, Balagurunathan Y, Rothberg JM, Sloane BF, Johnson J, Gatenby RA, Gillies RJ (2013) Acidity generated by the tumor microenvironment drives local invasion. Cancer Res 73 : $1524-1535$

27. Persi E, Duran-Frigola M, Damaghi M, Roush WR, Aloy P, Cleveland JL, Gillies RJ, Ruppin E (2018) Systems analysis of intracellular $\mathrm{pH}$ vulnerabilities for cancer therapy. Nat Commun 9:2997

28. Ryder C, McColl K, Zhong F, Distelhorst CW (2012) Acidosis promotes Bcl-2 family-mediated evasion of apoptosis: involvement of acid-sensing $\mathrm{G}$ protein-coupled receptor Gpr65 signaling to Mek/Erk. J Biol Chem 287:27863-27875

29. Wojtkowiak JW, Rothberg JM, Kumar V, Schramm KJ, Haller E, Proemsey JB, Lloyd MC, Sloane BF, Gillies RJ (2012) Chronic autophagy is a cellular adaptation to tumor acidic $\mathrm{pH}$ microenvironments. Cancer Res 72:3938-3947

30. Andreucci E, Ruzzolini J, Peppicelli S, Bianchini F, Laurenzana A, Carta F, Supuran CT, Calorini L (2019) The carbonic anhydrase IX inhibitor SLC-0111 sensitises cancer cells to conventional chemotherapy. J Enzyme Inhib Med Chem 34:117-123

31. Hu Y, Smyth GK (2009) ELDA: extreme limiting dilution analysis for comparing depleted and enriched populations in stem cell and other assays. Journal of Immunological Methods 347:70-78

32. Fabregat I, Malfettone A, Soukupova J (2016) New insights into the crossroads between EMT and stemness in the context of cancer. $\mathrm{J}$ Clin Med. 5:37

33. Ledaki I, McIntyre A, Wigfield S, Buffa F, McGowan S, Baban D, Li JL, Harris AL (2015) Carbonic anhydrase IX induction defines a heterogeneous cancer cell response to hypoxia and mediates stem cell-like properties and sensitivity to HDAC inhibition. Oncotarget 6:19413-19427

34. Supuran CT, Alterio V, Di Fiore A, D'Ambrosio K, Carta F, Monti SM et al (2018) Inhibition of carbonic anhydrase IX targets primary tumors, metastases, and cancer stem cells: three for the price of one. Med Res Rev 38:1799-1836 
35. Sugihara E, Saya H (2013) Complexity of cancer stem cells. Int J Cancer 132:1249-1259

36. Preca BT, Bajdak K, Mock K, Sundararajan V, Pfannstiel J, Maurer J, Wellner U, Hopt UT, Brummer T, Brabletz S, Brabletz T, Stemmler MP (2015) A self-enforcing CD44s/ZEB1 feedback loop maintains EMT and stemness properties in cancer cells. Int J Cancer 137:2566-2577

37. Hojo N, Huisken AL, Wang H, Chirshev E, Kim NS, Nguyen SM, Campos H, Glackin CA, Ioffe YJ, Unternaehrer JJ (2018) Snail knockdown reverses stemness and inhibits tumour growth in ovarian cancer. Sci Rep 8:8704

38. Huber MA, Azoitei N, Baumann B, Grünert S, Sommer A, Pehamberger H, Kraut N, Beug H, Wirth T (2004) NF-kappaB is essential for epithelial-mesenchymal transition and metastasis in a model of breast cancer progression. J Clin Invest 114:569-581

39. Nomura A, Majumder K, Giri B, Dauer P, Dudeja V, Roy S, Banerjee S, Saluja AK (2016) Inhibition of NF-kappa B pathway leads to deregulation of epithelial-mesenchymal transition and neural invasion in pancreatic cancer. Lab Invest 96:1268-1278

40. Dean M, Fojo T, Bates S (2005) Tumour stem cells and drug resistance. Nat Rev Cancer 5:275-284

41. Korkaya H, Wicha MS (2010) Cancer stem cells: nature versus nurture. Nat Cell Biol 12:419-421

42. Reya T, Morrison SJ, Clarke MF, Weissman IL (2001) Stem cells, cancer, and cancer stem cells. Nature 414:105-111

43. Plaks V, Kong N, Werb Z (2015) The cancer stem cell niche: how essential is the niche in regulating stemness of tumor cells? Cell Stem Cell 16:225-238

44. Yun Z, Lin Q (2014) Hypoxia and regulation of cancer cell stemness. Adv Exp Med Biol 772:41-53

45. Shibue T, Weinberg RA (2017) EMT, CSCs, and drug resistance: the mechanistic link and clinical implications. Nat Rev Clin Oncol 14:611-629

46. Mani SA, Guo W, Liao M-J, Eaton EN, Ayyanan A, Zhou AY et al (2008) The epithelial-mesenchymal transition generates cells with properties of stem cells. Cell 133:704-715

47. Liao S-Y, Lerman MI, Stanbridge EJ (2009) Expression of transmembrane carbonic anhydrases, CAIX and CAXII, in human development. BMC Dev Biol 9:22

48. Lock FE, McDonald PC, Lou Y, Serrano I, Chafe SC, Ostlund C et al (2013) Targeting carbonic anhydrase IX depletes breast cancer stem cells within the hypoxic niche. Oncogene 32:5210-5219

49. Huang S, Tang Y, Peng X, Cai X, Wa Q, Ren D, Li Q, Luo J, Li L, Zou X, Huang S (2016) Acidic extracellular $\mathrm{pH}$ promotes prostate cancer bone metastasis by enhancing PC-3 stem cell characteristics, cell invasiveness and VEGF-induced vasculogenesis of BM-EPCs. Oncol Rep 36:2025-2032

50. Filatova A, Seidel S, Böğürcü N, Gräf S, Garvalov BK, Acker T (2016) Acidosis acts through HSP90 in a PHD/VHL-independent manner to promote HIF function and stem cell maintenance in glioma. Cancer Res 76:5845-5856
51. Hu P, Li S, Tian N, Wu F, Hu Y, Li D, Qi Y, Wei Z, Wei Q, Li Y, Yin B, Jiang T, Yuan J, Qiang B, Han W, Peng X (2019) Acidosis enhances the self-renewal and mitochondrial respiration of stem cell-like glioma cells through CYP24A1-mediated reduction of vitamin D. Cell Death Dis 10:25

52. Avnet S, Di Pompo G, Chano T, Errani C, Ibrahim-Hashim A, Gillies RJ et al (2017) Cancer-associated mesenchymal stroma fosters the stemness of osteosarcoma cells in response to intratumoral acidosis via NF-KB activation. Int J Cancer. 140:1331-1345

53. Massa A, Perut F, Chano T, Woloszyk A, Mitsiadis TA, Avnet S et al (2017) The effect of extracellular acidosis on the behaviour of mesenchymal stem cells in vitro. Eur Cell Mater 33:252-267

54. Hazehara-Kunitomo Y, Hara ES, Ono M, Aung KT, Komi K, Pham HT, Akiyama K, Okada M, Oohashi T, Matsumoto T, Kuboki T (2019) Acidic pre-conditioning enhances the stem cell phenotype of human bone marrow stem/progenitor cells. Int J Mol Sci 20.

55. Som A, Bloch S, Ippolito JE, Achilefu S (2016) Acidic extracellular $\mathrm{pH}$ of tumors induces octamer-binding transcription factor $4 \mathrm{ex}-$ pression in murine fibroblasts in vitro and in vivo. Sci Rep 6:27803

56. Guo W, Keckesova Z, Donaher JL, Shibue T, Tischler V, Reinhardt F, Itzkovitz S, Noske A, Zürrer-Härdi U, Bell G, Tam WL, Mani SA, van Oudenaarden A, Weinberg RA (2012) Slug and Sox9 cooperatively determine the mammary stem cell state. Cell 148: $1015-1028$

57. Zakaria N, Mohd Yusoff N, Zakaria Z, Widera D, Yahaya BH (2018) Inhibition of NF-KB signaling reduces the stemness characteristics of lung cancer stem cells. Front Oncol 8:166

58. Xiang T, Long H, He L, Han X, Lin K, Liang Z, Zhuo W, Xie R, Zhu B (2015) Interleukin-17 produced by tumor microenvironment promotes self-renewal of CD133+ cancer stem-like cells in ovarian cancer. Oncogene 34:165-176

59. Santini R, Vinci MC, Pandolfi S, Penachioni JY, Montagnani V, Olivito B, Gattai R, Pimpinelli N, Gerlini G, Borgognoni L, Stecca B (2012) Hedgehog-GLI signaling drives self-renewal and tumorigenicity of human melanoma-initiating cells. Stem Cells 30:18081818

60. Silva AS, Yunes JA, Gillies RJ, Gatenby RA (2009) The potential role of systemic buffers in reducing intratumoral extracellular $\mathrm{pH}$ and acid-mediated invasion. Cancer Res 69:2677-2684

61. Wojtkowiak JW, Verduzco D, Schramm KJ, Gillies RJ (2011) Drug resistance and cellular adaptation to tumor acidic $\mathrm{pH}$ microenvironment. Mol Pharm 8:2032-2038

62. Vander Linden C, Corbet C (2019) Therapeutic targeting of cancer stem cells: integrating and exploiting the acidic niche. Front Oncol 9:159

63. Kemper K, de Goeje PL, Peeper DS, van Amerongen R (2014) Phenotype switching: tumor cell plasticity as a resistance mechanism and target for therapy. Cancer Res 74:5937-5941

Publisher's note Springer Nature remains neutral with regard to jurisdictional claims in published maps and institutional affiliations. 